\title{
Working
}

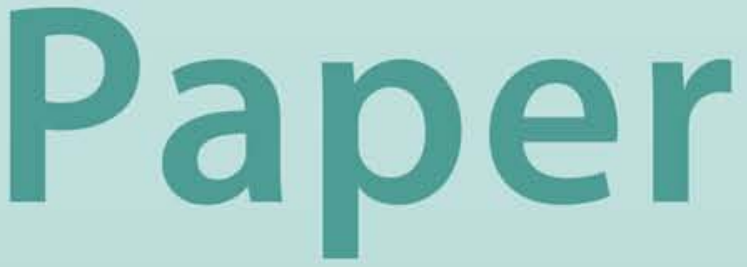


The Shortcomings of a Partial Release of Employment Protection Laws: The Case of the 2005 French Reform

Pierre Cahuc and Stéphane Carcillo 


\title{
IMF Working Paper
}

Fiscal Affairs Department

\section{The Shortcomings of a Partial Release of Employment Protection Laws: The Case of the 2005 French Reform ${ }^{1}$}

\section{Prepared by Pierre Cahuc and Stéphane Carcillo ${ }^{2}$}

Authorized for distribution by Gerd Schwartz

December 2006

\begin{abstract}

\section{This Working Paper should not be reported as representing the views of the IMF.} The views expressed in this Working Paper are those of the author(s) and do not necessarily represent those of the IMF or IMF policy. Working Papers describe research in progress by the author(s) and are published to elicit comments and to further debate.

This paper proposes an ex ante evaluation of the effects of new labor contracts such as the "Contrat Nouvelle Embauche" (CNE) introduced in France in 2005. The lessons we draw are of sufficiently general interest to be applicable to other countries or reforms of employment protection laws. Using a model that captures the characteristics of the French labor market, we simulate the effects of this reform on unemployment, employment, and welfare. We estimate that the CNE will lead to the creation of 70,000 additional jobs in the long run, but at the cost of a slight deterioration in welfare.
\end{abstract}

JEL Classification Numbers: J20, J41, J64, J65, J68

Keywords: Em ployment protection, labor contract, reform, search models

Authors' E-Mail Addresses: cahuc@ensae.fr; $\underline{\text { scarcillo@,imf.org }}$

\footnotetext{
${ }^{1}$ This Working Paper will be published as an Economic Policy web paper (www.economic-policy.org).

${ }^{2}$ Pierre Cahuc is Professor of Economics at the Université Paris 1, researcher at CREST, IZA, and CEPR. Stéphane Carcillo is an Economist at the Expenditure Policy Division of the IMF Fiscal Affairs Department. The authors thank Bruno Coquet, Etienne Lehmann, Fabrice Lenglart, Cyrile Nouveau, and André Zylberberg for helpful comments. The authors alone are responsible for any omissions or other errors.
} 


\section{Contents}

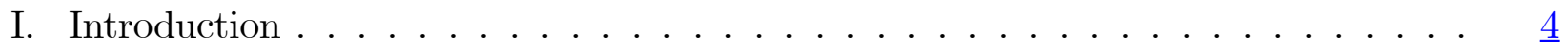

II. Regulatory Changes Brought About by the Introduction of the CNE . . . . . . $\underline{6}$

A. Advantages and Disadvantages of the New Contracts Relative to the CDD . . $\underline{7}$

B. Advantages and Disadvantages of the New Contracts Relative to the CDI . . . $\underline{8}$

C. Substitution Between New and Preexisting Labor Contracts . . . . . . . . . 10

III. Modeling the Labor Force Under Different Types of Contracts . . . . . . . . . . . 11

A. The Labor Market Prior to Introducing New Labor Contracts . . . . . . . . . 11

B. The Labor Market After Introducing New Labor Contracts . . . . . . . . . . . $\underline{13}$

IV.Evaluating the Impact of the New Labor Contracts . . . . . . . . . . . . . . 15

A. Calibration of the Model . . . . . . . . . . . . . . . . . $\frac{15}{15}$

B. Expected Impact in Job Creation . . . . . . . . . . . . . . . . . . 17

C. Expected Impact on Welfare and Labor Participation . . . . . . . . . . . . . . 19

D. Expected Impact on Unemployment . . . . . . . . . . . . . . . . . . . $\underline{20}$

E. Robustness of Results . . . . . . . . . . . . . . . . . . . . 22

V. Conclusion: The Advantages of a Single Labor Contract? . . . . . . . . . . . $\underline{25}$

Appendix: The Model . . . . . . . . . . . . . . . . . . . . $\underline{28}$

A. The Labor Market With CDD and CDI Contracts . . . . . . . . . . . . $\underline{28}$

B. The Labor Market After the Introduction of the CNE . . . . . . . . . . . . $\underline{33}$

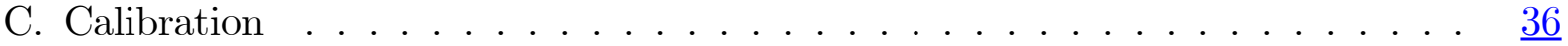

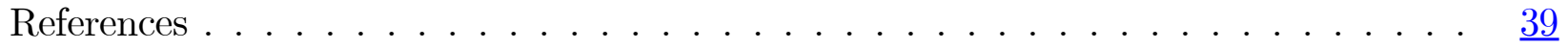

Tables

1. The Robustness of the Model Under Different Parameter Values . . . . . . . . . $\underline{24}$

2. Baseline Parameter Values for the Simulation of the Model . . . . . . . . . . $\underline{38}$

Figures

1. The Structure of the Labor Market Before the Introduction of CNE-type Contracts $\underline{13}$

2. The Structure of the Labor Market After the Introduction of CNE-type Contracts 14

3. Employment Rate and Number of Net Jobs Created After the Reform With No Changes in the Participation Rate . . . . . . . . . . . . . . . . . . . . 18

4. Number of Net Jobs Created After the Reform for Firms With Less Than 20 Employees . . . . . . . . . . . . . . . . . . . . 19

5. Employment Rate and Number of Net Jobs Created After the Reform With Changes in the Participation Rate . . . . . . . . . . . . . . . . . . 20

6. Labor-Force and Participation Rate After the Reform . . . . . . . . . . . . . $\underline{21}$ 
7. Unemployment Rate and Variation in the Number of Unemployed After the Reform With No Change in the Participation Rate . . . . . . . . . . . . . 21

8. Unemployment and Variation in the Number of Unemployed After the Reform With a Change in the Participation Rate . . . . . . . . . . . . . . . 22

9. Employment Rate, Unemployment Rate, Net Number of Jobs Created, and Variation in the Number of Unemployed Under an Alternative Reform . . . . . . . . $\underline{26}$ 


\section{Introduction}

The implementation of the New Employment Contract (CNE) has introduced important changes that may have profound repercussions on the performance of the French labor market. The CNE is an indefinite-term contract that applies exclusively to small businesses of no more than twenty employees. ${ }^{3}$ Established on August 4th, 2005, the CNE is a notable break with preexisting labor contracts - namely the common right indefinite-term contract (CDI) and the fixed-term contract (CDD) - on two accounts. For one, during the first two years, the CNE allows the employer to terminate the contract without having to provide an explanation; secondly, during those first two years, employers need only give their employees two weeks notice before dismissal, and after six months the notice period is extended to one month. ${ }^{4}$ The employer's obligation has been essentially reduced to complying with the severance procedure, which is also simplified under the CNE.

The CNE's effectiveness is often maintained by pointing to the 440,000 such contracts that were established during the first eight months of its existence (based on the statistics drawn from French firms' compulsory hiring count $)^{5}$. It turns out this statistic does little more than to veil the difficulty of determining the reform's overall impact on job creation. We list a few reasons below.

For one, such a statistic does not capture the net variation of the number of jobs in the labor pool - it only reflects the number of hirings using the CNE. It is impossible to readily determine the reform's impact on the overall number of existing jobs from this statistic without taking into account labor flows. For instance, it is worth noting that over 6 million workers flow in and out of employment in France every year. Furthermore, it is worth remembering that job turnover is higher in small businesses. In any given month, French businesses of less than 20 employees hire an estimated 250,000 new workers. Thus, the 440,000 CNE contracts that were established eight months after its outset only account for as much as 20 percent of worker flows among small businesses.

Secondly, it is reasonable to assume that a number of jobs created under the CNE have simply substituted jobs that would have been created under the CDD or CDI (had the

\footnotetext{
${ }^{3}$ The CNE must be distinguished from the CPE (New Employment Contract). The latter, introduced in February 2006, was very similar to the CNE, but was restricted to people under 26 and available to firms with more than 20 employees. After several weeks of strikes and demonstrations, the CPE was repealed by the government in April 2006.

${ }^{4}$ The CNE is a written contract subject to the legal and customary framework in effect at the time of its signature. However, during the first two years of the contract, certain articles of the labor-code are void: L. 122-4 to L. 122-11 (these relate to the conditions in which a CDI is severed, the firing process for dismissals that are not economically motivated, serious faults, the circumstances surrounding a firing notice, the conditions in which severance payments are made, etc.); L.122-13 to L.122-14-14 (firing procedure, the substantive power vested in the judge definition of real and serious cause for dismissal, severance pay for unjustified or unlawful dismissal, etc.); L.321-1 to L.321-17 (economically motivated dismissals, definition of motive, firing procedure, saving a position, rehiring privilege, the providing of mandatory notice and information to the administration, rules regarding job conversions, the administration of justice, etc.)

${ }^{5}$ See www.acoss.urssaf.fr for the detailed figures.
} 
CNE not existed).

Thirdly, we do not know a priori the survival rate of CNE jobs. Given the relative flexibility of the new contracts, it is likely that CNE jobs will be more easily destroyed than CDD and CDI contracts. In particular, employers may have a powerful incentive to terminate these contracts at the end of their two-year trial (or "qualifying") period in order to avoid entering into the more binding phase of the contract with more stringent dismissal restrictions (i.e., a CDI with two years of seniority). Consequently, even if the CNE reform were to promote employment in the short run, the discrete jump in firing restrictions between the CNE and the CDI after the two-year qualifying period could significantly reduce its long-term impact on employment and unemployment. In fact, since the new contract fosters both job creation and job destruction, the CNE could even increase unemployment in the long run. Ultimately, it all depends on how the job creation and job destruction brought about by the reform off-set each other. The a priori ambiguity of policy, a phenomenon all too familiar to economists, calls for a deeper understanding of the reform's influence on unemployment and job creation.

In order to evaluate the impact of the CNE on unemployment, labor participation, employment, and job "precariousness" (instability), ${ }^{6}$ one must consider a dynamic representation of the labor market that reflects the significant labor flows observed today. With this in mind, we have created a model of the French labor market that captures both the extent of worker flows, as well as job opportunities under different labor contracts. Our model rests on a number of works published since 1990, the date at which available data started revealing a significant (and previously overlooked) degree of job creation and destruction, as well as significant worker flows. ${ }^{7}$ A few of these works have already analyzed the consequences of making fixed-term contracts available to employers, and conclude that these contracts lead to a minor decrease in unemployment at best, and may even lead to an increase in unemployment. ${ }^{8}$ Indeed, the apparent job creation brought about by an increase in fixed-term contracts may be more than offset by a decrease in the use of permanent contracts.

We intend to build upon these works by explicitly modeling the introduction of the CNE, which, unlike the CDD, has the important distinction of not specifying an expiration date. Our model, which captures the French labor market before and after the implementation of CNE-type contracts, serves to evaluate the effectiveness of such contracts in reducing unemployment and creating jobs. ${ }^{9}$ The model was constructed with the ambition of accurately reflecting the chief characteristics of the French labor market before the reform,

\footnotetext{
${ }^{6}$ We explicitly define the notion of "precariousness" below. In English, precariousness does not fully capture the meaning of precarité. We can use "job instability" for want of a better term.

${ }^{7}$ Pissarides (2000) is an essential reference.

${ }^{8}$ Blanchard and Landier (2002); and Cahuc and Postel-Vinay (2002).

${ }^{9}$ Within a similar search framework, Zhou (2006) considers the CNE as equivalent to a fixed-duration contract with no hiring and firing restrictions, and comes up with the result that the unemployment rate could raise after the reform. In contrast, our paper is based on a more realistic representation of the French labor market: fixed-term contracts can be converted into long-term contracts, and the CNE is explicitly introduced as a new distinct form of labor contract. The impact of the reform on labor market participation is also analyzed in our paper.
} 
with the goal of estimating accurate orders of magnitude for the reform's effect on unemployment, job creation, and other variables of interest. The model considers a scenario in which CNE-type contracts are introduced into the French economy as a whole. Our analysis suggests that introducing the CNE increases both job creation and destruction, leading to a modest net increase of approximately 80,000 jobs during the first four years of the reform, and 70,000 jobs after 10 years. Furthermore, by significantly reducing job stability, and only providing for a minor decrease in unemployment, we find that a CNE-type reform may reduce jobseekers' welfare. Specifically, we measure the average decrease in jobseekers' welfare to be equivalent to a $1 / 2$ percent drop in revenue, which triggers a slight reduction in the participation rate. In sum, our model suggests that in the long run the CNE may lead to a very modest increase in employment, but at the cost of a slight deterioration in welfare for those seeking employment. Bearing this in mind, we suggest that complementing CNE-type contracts with a labor reform that (1) reduces the economic cost of firing, but (2) offers more generous severance pay is likely to have a significant positive effect on both job creation and welfare.

The paper is organized as follows. Section II briefly documents the regulatory changes brought about by the CNE. Section III outlines the theoretical framework and the key numbers we used for calibration (the model itself is presented in the Appendix). Section IV presents our results regarding unemployment, job creation, labor participation, and welfare.

\section{Regulatory Changes Brought About by the Introduction of the CNE}

The CNE is an indefinite-term contract that employers can terminate without having to provide an explanation during a two-year qualifying period. Within this period, after the first month employers are required to give two weeks notice for severance of the contract, and after six months the notice period is extended to one month. After this two-year period, if the job survives, the regular protection laws for indefinite-term contracts apply. Prior to this labor reform, the CDD had the exclusive benefit of providing businesses with the flexibility of firing an employee at a low legal risk (i.e., at a low cost). Namely, at the time, CDD contracts were the only alternative to CDI contracts which, given their more stringent firing restrictions, bear greater legal risks for the employer once the trial period is over. ${ }^{10}$ Let us now delve into the advantages and disadvantages of introducing CNE-type contracts from the standpoint of employers and employees, respectively. ${ }^{11}$

\footnotetext{
${ }^{10}$ Aside from the CDD, temporary contracts are also used in France, but with less frequency as they are relatively costly and mostly used for very short assignments.

${ }^{11}$ One main exception being the contrat d'usage, which is a special short-term contract reserved for certain jobs in specific sectors. Jobs under such a contract have the following characteristics: (1) severance pay is not obligatory (Article L 122-3-4); (2) the absence of a waiting period between the signature of two consecutive CDD contracts (Article L 122-3-11); (3) the absence of an official expiration date for the contract (Article L 122-1-2). The contrat d'usage may be used in the following industries: forestry, naval repair, moving, hospitality industry, performances, cultural activities, audiovisual, informational, teaching,
} 


\section{A. Advantages and Disadvantages of the New Contracts Relative to the CDD}

A priori, CNE-type contracts offer a number of advantages for employers compared to the CDD, and even more advantages with respect to the CDI. ${ }^{12}$ The CNE reform also provides a priori advantages for employees, but their gains are better assessed a posteriori (by observing job creation in the long run).

\section{For the employer}

- Advantages: The new contracts offer three main advantages to the employer. First and foremost, an employer need not justify his use of a CNE, whereas using a CDD contract requires legal validation (French law stipulates 11 provisions justifying the use of a CDD). ${ }^{13}$ Furthermore, the CNE offers employers with the liberty of dismissing an employee at any time without having to provide legally-imposed justifications. ${ }^{14}$ Lastly, it is slightly less costly for the firm to sever a CNE contract than to bear the termination costs of a CDD contract (since the termination cost in the form of a payment to the employee at the end of a CDD, is subject to social taxes, whereas CNE severance pay is not).

- Disadvantages: The new contracts bear a few disadvantages - two chief disadvantages are noted here. First, if at the end of a CDD the employer chooses to rehire the employee under a CDI, ${ }^{15}$ the employee's seniority is set back to zero. On the other hand, an employee that endures the CNE's two-year qualifying period benefits from the equivalent of two years of seniority under a CDI. In other words, when converting a CNE contract into a permanent contract the employer incurs greater firing restrictions than if he were to rehire a CDD employee under a CDI contract.

movie production, polls, phonographic production, recreation and vacationing centers, stocking of meat, professional sports, construction work conducted abroad, engineering, research and technical cooperation conducted abroad, third-party associations (associations intermédiaires), personal assistance associations (associations de services aux personnes), scientific research conducted at international conventions.

${ }^{12}$ These reforms have a broad range of applications. Nearly every type of job can be affected by the CNE, save short-term, seasonal contracts. In particular, professions in the following industries are likely to be influenced: industrial and commercial activities, agricultural jobs that make use of article 1144 (1-7, 9-10) of the rural code, liberal professions, public and ministerial office-holders, house and family assistants, concierges and receptionists, maternity assistants, members of civil society groups, labor union members, sociétés mutualistes, private social security firms and associations, private law organizations (associations ou organisme de droit privé).

${ }^{13}$ In practice, given that 70 percent of all employees are hired under CDD contracts, it is obvious that adherence to the 11 legal provisions is often misreported. Still, even misreporting compliance is costly in terms of time.

${ }^{14} \mathrm{~A}$ CDD contract has a very short trial-period, and in order to sever the contract, the employer must provide evidence of serious fault. Neither employee underperformance, nor economic pressure, nor even insolvent liquidation are sufficient grounds to dismiss an employee without the risk of legal contestation.

${ }^{15}$ For an employer, firing an employee with two years of seniority bears certain costs: severance pay (both legal and conventional), legal costs (a delay of 12-24 months is expected for a meeting before the industrial tribunal), and at least six-month's worth of gross salary for a dismissal that is not justified by law. 
Secondly, a degree of uncertainty exists in court regarding the legal treatment of severing CNE contracts: it is still possible to challenge a dismissal for breach of right, as was recently pointed out by the French State Council. ${ }^{16}$

\section{For the employee}

- Advantages: The employee benefits from two types of advantages with respect to the CDD. First, in the event of dismissal, the CNE provides support more readily: after having reached four months of seniority the employee benefits from a daily payment of 16.40 euros for one month. However, under any other contract, an employee must have at least six months of seniority, during which time he must have made mandatory contributions to the national unemployment insurance scheme, before being eligible for unemployment benefit in the event of dismissal. Secondly, while the CNE is de jure considered a CDI for third parties (banks, creditors, etc.), in practice it remains to be seen whether CNE contracts will benefit from this distinction instead of being pooled with CDD contracts.

- Disadvantages: Under the CDD, the employee is guaranteed his salary up until the official, legally-bound termination of his contract, even if the employer chooses to lay him off beforehand. Since no such official expiration date exists under a CNE, the employee obviously ceases to benefit from a full salary in the event of being laid off. If an employee is laid off under the CNE, he bears the added disadvantage of benefiting from less severance pay than under a CDD (8 percent and 10 percent of accrued income, respectively).

\section{B. Advantages and Disadvantages of the New Contracts Relative to the CDI}

\section{For the employer}

- Advantages: The CNE provides the employer with near-unconditional flexibility when it comes to firing an employee, since the contract can be terminated without having to offer an explanation. ${ }^{17}$ The employer need only respect a simplified firing procedure, and he benefits from a shorter notice period. ${ }^{18}$ As mentioned above, two

\footnotetext{
${ }^{16}$ In particular, the French State Council judged that an employee could still challenge the severance of a CNE before the industrial council if the dismissal is deemed "abusive." Thus, the CNE's jurisprudence may be based on legal grounds similar to those that existed prior to the 1973 French labor law (which imposed proof of "real and serious grounds" for firing an employee).

${ }^{17}$ Employees are still protected against dismissal under certain conditions (maternity leave, accidents, health issues, etc.).

${ }^{18}$ The procedure is simplified to sending a dismissal notice by certified mail, without having to provide an explanation. Should the employer deem the employee is guilty of serious fault, the standard disciplinary procedure is followed as required by law. Dismissing a CNE worker that is part of a labor union must also comply with the legal conditions set out by the contract.
} 
weeks notice is required if severance of the contract occurs after the first month, and one month notice if severance occurs after six-months into the contract (the CDI requires 1-3 months of notice). Moreover, in principle the CNE provides the employer with much less uncertainty as to the legal outcome of a potential contestation on behalf of the employee (in particular, legal challenges cannot take place without compelling grounds). However, as noted above, this advantage must be qualified seeing as the employee can still challenge a dismissal for breach of rights. ${ }^{19}$

- Disadvantages: Laying-off an employee entails an immediate cost ${ }^{20}$ to employers under CNE-type contracts, whereas with a CDI next to nothing is due during the first two years (there is no legally-imposed severance pay, and when companies offer such pay on their own accord, it is customarily very meager). Moreover, after severing a CNE, a waiting period of three months must be respected before rehiring the same employee under a CNE.

\section{For the employee}

- Advantages: CNE-type contracts offer more substantial severance pay during the first two years in the event of a layoff: as mentioned above, an employee under a CDI with less than two years of seniority is not legally entitled to severance pay, ${ }^{21}$ and has less rights in the court of law. In addition, the CNE provides support more readily in the event of unemployment: 16.40 euros per day for one month, after four months of seniority (versus a minimum of 6 months of seniority and mandatory contributions under any other contract).

- Disadvantages: For one, CNE-type contracts imply less job security during the first two years of the contract and offer a limited degree of legal recourse. Secondly, the firing procedure is expeditious, ${ }^{22}$ and the notice period is shorter (two weeks or one month for a CNE, versus 1-3 months for a CDI).

\footnotetext{
${ }^{19}$ Under the CNE, absence of formal, written grounds for dismissing an employee does not free the employer from potentially having to justify "real and serious grounds" for severance of the contract in court. Employees that suspect they have been fired under conditions that fail to comply with French labor laws may bring their case to the industrial tribunal for breach of rights.

${ }^{20}$ The immediate cost to the firm is 10 percent of the total gross salary paid since the beginning of the contract: 80 percent of this cost goes to the dismissed employee, and the remaining 20 percent is a tax paid to the state.

${ }^{21}$ According to the labor code, all workers under an indefinite term contract with less than two years of seniority are not entitled to legal severance pay. Moreover, more often than not, these workers do not receive conventional severance pay; this latter pay is specific to each industry and determined by periodic intra-industry conventions. However, all workers with 2 or more years of seniority who are dismissed (for reasons other than committing a serious fault) are entitled to severance pay. The minimum severance pay required by law is equal to $1 / 10$ of a reference monthly salary, based on each year of seniority. After 10 years of seniority an additional $1 / 15$ of the reference monthly salary is added to the severance pay. When a dismissal is grounded in purely economic reasons (e.g., downsizing), severance pay is increased: for workers with less than ten years of seniority, $2 / 10$ of the monthly salary; for workers with more than ten years of seniority, $2 / 15$ of the monthly salary is added to the original $2 / 10$ (i.e., for a total of $1 / 3$ of monthly salary).

${ }^{22}$ The severance process is longer and can be more complex for a CDI contract.
} 


\section{Substitution Between New and Preexisting Labor Contracts}

Listing the advantages and disadvantages of the CNE enables us to gain insight into the extent of the new contracts' expected replacement of CDD and CDI contracts. On the whole, it would seem that CNE-type contracts provide more advantages than disadvantages for businesses. Indeed, the disadvantages seem relatively modest. Nonetheless, a complete substitution of CDD and CDI contracts by CNE-type contracts seems unrealistic.

The degree to which CDD contracts are used after the introduction of the CNE reform will depend on whether such contracts retain a distinct function. For instance, CDD contracts that were used as a means of testing new employees for a few months before adopting a CDI will most likely be replaced by CNE-type contracts. However, a company may deem CDD contracts a useful means of adapting to predictable fluctuations in demand or to deal with temporary absences in their workforce. In establishing a contractual severance date, the CDD has the advantage of avoiding a standard lay-off. For even if laying-off an employee is greatly facilitated under a CNE, the very process of firing involves a "human cost" that is absent under a CDD's planned severance date. Thus, the CNE may not be the most suitable contract for businesses when dealing with predictable fluctuations in demand, or when replacing an employee that is temporarily on leave. ${ }^{23}$

Employers are likely to opt for a near-complete substitution of the CDI with CNE-type contracts due to their significantly longer qualification period (since a longer trial period reduces the risk of a costly severance at a future date). Nonetheless, we must bear in mind that the choice of a contract is not exclusively determined by the employer, but may be influenced by bargaining between the two parties. Moreover, it may be in the employer's best interest to hire the more promising employees under a more secure contract, as an expression of approval and encouragement that may positively influence employee commitment.

The above suggests that one should expect a high degree of substitution. Intuitively, this substitution could seriously undermine the CNE labor reform's ambition of creating a significant number of jobs. Indeed, under the extreme case of a complete substitution of CDD and CDI contracts, there is no net job creation. However, even if the number of jobs stays more or less constant, substitution implies flooding the labor market with very flexible contracts, which may increase the labor turnover rate. If, on the other hand, net jobs are created under the CNE in spite of a high degree of substitution, then perhaps unemployment can be reduced despite having facilitated the firing process. With this in mind, we can see how nothing should be deduced from a mere statistic reflecting an increase in CNE contracts: little can be drawn from the 440,000 CNE contracts that were established during the first eight months after its outset.

\footnotetext{
${ }^{23}$ Drawing on the same argument, we can expect substitution between CNE contracts and temp contracts to be fairly limited. Temporary contracts are relatively more costly for firms than CDD contracts, making the former of relatively short duration. In theory, CNE contracts are both less onerous and just as flexible as temporary contracts, making them a good replacement for temporary contracts that are two weeks or longer. In reality, most temporary work is of very short duration, and we expect the CNE's effect on temporary contracts to be trivial.
} 


\section{Modeling the Labor Force Under Different Types of Contracts}

Our evaluation of the consequences of introducing CNE-type contracts into the French labor market is conducted in two steps. First, we will consider a model of the labor market with CDD and CDI contracts. This model accurately reflects the principal characteristics of the French labor market, such as the rate and average duration of unemployment, the average length of CDD and CDI contracts, and the proportion of CDD contracts in the economy. In turn, this theoretical framework is used to analyze the impact of introducing CNE-type contracts into the labor market.

\section{A. The Labor Market Prior to Introducing New Labor Contracts}

\section{Job creation}

At any given point in time, the number of jobs offered in the labor market is determined by a free-entry condition: firms create jobs as long as they perceive opportunities for profit. That said, seeing as the recruitment process can be time-consuming and costly, a job offer rarely turns immediately into employment. Our model takes into account such hiring costs, as well as the way these costs vary with respect to the unemployment rate. In particular, if the unemployment rate is high, firms can find a suitable employee more readily, which reduces the cost of hiring. Moreover, firms are confronted with varying degrees of uncertainty: the profitability of each job contract varies (differently) throughout time. Given this uncertainty, employers have a natural preference towards using CDD rather than CDI contracts, even if this means (1) bearing higher total recruitment costs, since hiring is more frequent, and (2) running the risk of agreeing to a contract that becomes unprofitable before its legal expiration (i.e., wages are a sunk cost). However, seeing as French labor laws limit the use of CDD contracts, our model assumes an upper bound for the proportion of such contracts used by each firm. Bearing this in mind, we assume the French economy is made up of only CDD and CDI contracts for the time being.

\section{Job destruction}

In an economy with exclusively CDD and CDI contracts, firms can fire employees under two types of scenarios.

When a CDD reaches its date of expiration, employees lose their job unless the firm chooses to rehire them under a CDI contract. An obligatory termination payment equal to 10 percent of accrued income is awarded to employees who are not rehired. In the event an employee's contract is no longer profitable to a firm, we assume that the firm has no choice but to maintain the CDD until its date of expiration. For the sake of simplicity, we also assume that the duration of a CDD is not chosen by firms, but imposed. The length of this imposed value is not arbitrary, but the average length of CDD contracts observed in the French economy. 
The firm can also fire employees under a CDI contract, which generally occurs when maintaining the contract becomes unprofitable. In this case, we estimate the severance cost as corresponding to the employee's annual salary, which is roughly equal to the average cost of a dismissal in France (Kramarz and Michaud, 2004).

\section{Wage setting}

The wage rate is taken as a given, imposed on both employers and employees. This hypothesis accurately captures the segment of the labor market in which employees are paid minimum wage. Thus, our analysis of the introduction of CNE contracts is most accurate for this particular segment of the labor market. For wages that are above minimum wage, an approach that captures the bargaining process involved in determining salaries would be more appropriate. For instance, such an approach would account for an increase in salaries if the CNE reform lowers the unemployment rate. The expected general increase in salaries would in turn reduce the long-run impact CNE contracts have on reducing unemployment (but without annulling it altogether). As a result, our simplifying assumption that wages are held constant will tend to exaggerate the reform's effect on the unemployment rate.

\section{Employment and unemployment}

The rate of unemployment and job creation are determined by the firms' demand for labor and the labor force's supply. As we have just seen, the supply of jobs is determined by the free-entry condition, while the size of the labor force is essentially determined by competing incentives to enter or exit the labor force. Intuitively, any change in the labor market that increases the expected benefits of working or searching for a job will increase the size of the labor force. Recall that a person who enters the labor market starts off by looking for a job. Given the imperfect flow of information, this process can be both long and costly: for any given position, the coexistence of a matching, but undiscovered supply and demand of labor is not uncommon. ${ }^{24}$ Next, once a person has been hired, he can lose his job at any given time, due to changes in the expected profitability of maintaining the contract for the employer. If need be, this person may choose to stay in the labor force as a jobseeker and become reemployed after an uncertain amount of time.

With this in mind, we can see how the fluctuations of employment and unemployment in a given labor market are influenced by the type of labor contracts used. For instance, given their relative flexibility, CDD contracts tend to increase both the rate of hire and the rate of dismissal. Conversely, CDI contracts tend to inhibit both hiring and firing, as severing such a contract is more costly. Figure 1 provides an illustration of the labor market's structure.

\footnotetext{
${ }^{24}$ The coexistence of a matching, but undiscovered, pool of labor supply and labor demand is characteristic of all labor markets. The relationship between the supply and demand of labor is habitually referred to as the Beveridge curve.
} 
Figure 1. The Structure of the Labor Market Before the Introduction of CNE-type Contracts

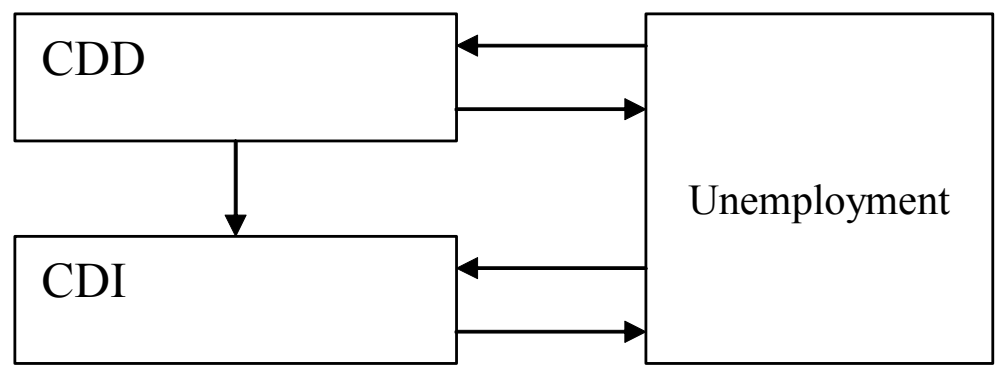

\section{B. The Labor Market After Introducing New Labor Contracts}

\section{Job creation}

We assume that CNE-type contracts provide the double benefit of having a lower severance cost than CDIs, as well as providing for greater flexibility than CDDs. Thus, employers will unambiguously prefer to hire employees under the CNE after its introduction, rather than to use CDI or CDD contracts. Consequently, our model assumes a gradual, complete replacement of CDD contracts. Given that CNE contracts must be turned into CDI contracts after the two-year trial period, these latter contracts outlive the CNE labor reform. As discussed earlier, in reality CDD contracts continue to be useful to employers, so their complete replacement is a simplifying assumption that tends to exaggerate the beneficial effect of CNE contracts on unemployment and employment.

\section{Job destruction}

The length of the trial period for CNE-type contracts is at most two years. During this period, firms can fire an employee at any given time, should maintaining the contract become unprofitable. The firm is legally required to pay a severance cost equal to 10 percent of the total gross salary paid since the beginning of the contract: 80 percent of this cost goes to the dismissed employee, and the remaining 20 percent is a tax paid to the state. If the employee endures the two-year trial period, the firm must then decide whether to convert the CNE contract into a CDI, or to lay-off the worker and bear the 10 percent severance cost. In turn, a firm may sever a CDI contract if keeping the employee becomes unprofitable, but at a higher separation cost equal to one year's worth of salary (on average). It is worth noting that firms do convert a number of CNE contracts into CDI, deeming that the productivity of certain workers is sufficiently high to cover the risk of a more costly severance.

\section{Employment and unemployment}

Employment, unemployment, and the labor force participation rate are all determined by the supply and demand for labor, as was the case prior to the introduction of the CNE contracts. In particular, the employment and unemployment rates are determined by 
Figure 2. The Structure of the Labor Market After the Introduction of CNE-type Contracts

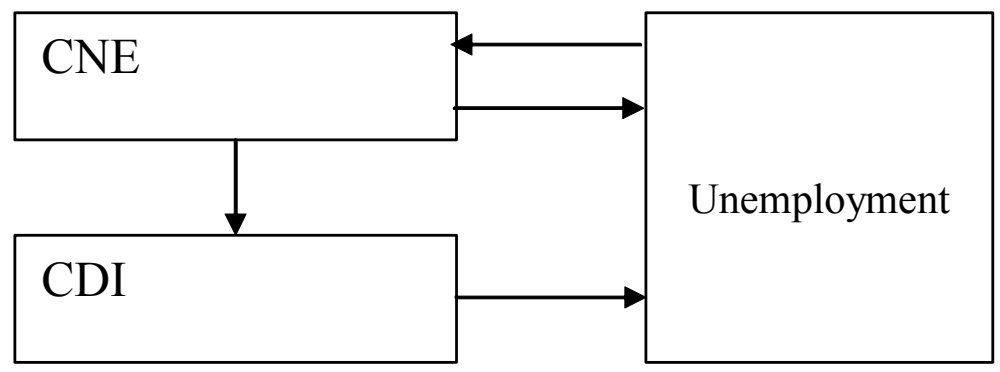

constant flows in hiring (under CNE contracts only), firing (under CNE and CDI contracts), and the converting of CNE contracts into CDIs. After the introduction of the CNE, all vacant jobs offered are under CNE contracts, and no jobs offered are CDD or CDI contracts. Given that CNE contracts offer more flexibility to the employer than CDD and CDI, the rate of job creation increases. Little by little, the share of CDD contracts in the labor pool decreases while the share of CNE jobs increases. In time, the CDD disappears and CNE contracts add up to a greater share of the labor pool than the CDD did before the labor reform. This new market structure, which reflects the complete replacement of CDD contracts, is illustrated in Figure 2.

In the long run, the impact of the $\mathrm{CNE}$ on the unemployment rate is ambiguous. While the flexible nature of this contract initially leads to job creation, the discontinuous rise in severance costs when converting a CNE into a CDI may compel employers to fire a large proportion of employees after the two-year trial period. After a rise in employment during the first two years of the CNE reform, the discontinuous jump in severance costs may create a threshold effect that results in a degree of job destruction that is equal to, or even greater than, the number of jobs created.

The relationship between unemployment rate and employment depends on fluctuations in the labor force participation rate, ${ }^{25}$ fluctuations which are taken into account in our model. If the introduction of CNE contracts increases the expected welfare of working or searching for a job, then a portion of the population may be incited to join the labor force (which favors employment), but unemployment may increase if the job search process proves long and unfruitful. Conversely, if the new contracts were to decrease expected welfare, people would choose to exit the labor force, ${ }^{26}$ which in turn decreases both employment and unemployment.

\footnotetext{
${ }^{25}$ Recall that total employment is equal to the labor force 1 multiplied by $(1-u)$, where $u$ is the unemployment rate. The employment rate is equal to the total employment divided by the working-age population, $L$. Thus, we have $\ell(1-u) / L$ for the employment rate. The labor force participation rate is equal the labor force divided by the working-age population, $l / L$.

${ }^{26}$ A certain segment of the labor force is deemed "marginal" in the sense that these workers may decide to enter or exit the labor force after a relatively modest change in the job environment.
} 


\section{A measure of "precariousness": welfare}

It is often argued that a labor reform that increases the number of "unstable" or "precarious" jobs is misguided. That said, the concept of "precariousness" remains vague, and warrants a definition on the basis of clear criteria. For instance, is precariousness reduced if unemployment decreases via a higher turnover rate (i.e., more frequent, but briefer unemployment spells)? Intuitively, the concept needs to take into account the interplay between a reduction in unemployment and a general increase in the turnover rate (i.e., increase in job-instability).

An economic analysis may shed light on a definition of "precariousness." Namely, comparing the expected discounted utility of the unemployed ${ }^{27}$ before and after the CNE labor reform can help us evaluate the potential trade-off between a labor market with more, but less secure jobs. This trade-off must take into account the degree to which individuals in the labor force are risk-averse. For an unemployed individual with a high degree of risk-aversion, the benefit of having access to more jobs may be outweighed by the short-lived nature of these jobs. Once we have an empirical estimate of risk-aversion, we can evaluate whether the interplay between job creation and job-instability tends to increase, or decrease, average welfare. In sum, we can use the expected change in welfare induced by the CNE as a proxy for the change in "precariousness" perceived by French jobseekers after the reform.

\section{Evaluating the Impact of the New Labor Contracts}

From a strictly theoretical standpoint, the model presented above cannot evaluate the CNE labor reform's impact on employment and unemployment. A number of questions remain: what will be the turnover rate for CNE jobs? Will this rate dampen, annul, or perhaps even outweigh the welfare increasing effects of job creation? Will the discontinuous jump in worker protection between CNE and CDI contracts considerably curb the labor reform's ability to reduce unemployment in the medium run? Will the workers' average welfare increase or decrease? In order to shed light on these questions, we must now move on to a numerical application of our theoretical framework. After justifying the values used to calibrate our model, we will present our numerical assessment of the effect of CNE contracts on employment, labor participation, and unemployment.

\section{A. Calibration of the Model}

The model captures the chief characteristics of the French labor market just before the introduction of the CNE (i.e., the unemployment rate, the average duration of

\footnotetext{
${ }^{27}$ That is, the average expected indirect utility (discounted of future gains) that is derived from the job search process.
} 
unemployment spells, the average duration of jobs, the proportion of CDD contracts, and severance costs as a function of salary). ${ }^{28}$ Calibrated in such a way, our model can then be used to measure the reform's effect on the performance of the French labor market and on welfare. Values for our parameters were based on the most recent available data, which are drawn from the years 2002-05, depending on the source. ${ }^{29}$

Our model takes into account the entirety of the French population that is of working age (i.e., between 15-64 years of age). The economy is taken to have a 10 percent unemployment rate, a participation rate of 70 percent, and an employment rate of 63 percent. ${ }^{30}$ Drawing from the most recent available data in 2003, the average duration of employment (in the non-agricultural for-profit sector) is equal to 110 months, and the average duration of an unemployment spell is 12 months. The fraction of CDD contracts in the labor market (excluding very short, seasonal contracts) is 5 percent, ${ }^{31}$ and they account for 70 percent of all starting contracts. Moreover, excluding seasonal contracts, 70 percent of CDD contracts are converted into CDIs (Goux, Maurin, and Pauchet, 2001). The length of CDD contracts is more difficult to determine, and has been reported as either 5 months, or 10-12 months, depending on the source. ${ }^{32}$ We therefore adopt an intermediate value of 8 months for the average length of CDD contracts.

The legal obligations of each contract are also taken into consideration. The severance cost under CDD contracts is 10 percent of the total gross wage paid since the beginning of the contract - unless the contract is transformed into a CDI. The cost of severing a CDI is equal to one year's worth of salary (Kramarz and Michaud, 2004). ${ }^{33}$ We assume that one-third of these severance costs are procedural in nature (i.e., paid to third parties), while the remainder corresponds to the worker's severance compensation. The trial period under a CNE contract is two years, and the severance cost is equal to 8 percent of the total gross salary paid. A jobseeker's net income is taken to be 70 percent of his net salary.

Other structural characteristics of the French labor market are also reflected in our model.

\footnotetext{
${ }^{28}$ Calibration of the model can be found in the Appendix.

${ }^{29}$ Data for the duration of employment and unemployment spells were not available for 2005. Our calculations are based on data drawn from previous years.

${ }^{30}$ Statistics drawn from the INSEE 2003 Labor Survey (Enquête Emploi, 2003).

${ }^{31}$ Only CDD contracts of more than 30 days in duration, and that are in the non-agricultural trade sector are considered here (INSEE 2003 Labor Survey). The share of short-term employment in the labor pool that also includes temporary jobs and government subsidized employment is significantly higher (approximately 12 percent).

${ }^{32}$ According to EMMO-DMMO (Survey on Labour Flows, 2002) the average duration of a CDD job is 5 months, whereas the INSEE 2003 Labor Survey holds the average duration to be 10-12 months. This notable difference is present across all years considered. The EMMO-DMMO data is provided by firms, while the INSEE data is based on questionnaires completed by households. The former data set tends to have a downward bias on estimated CDD length (accounting for successive renewals of contracts on the same jobs as separate contracts), while the latter tends to overstate CDD duration (difficulty in accounting for very short contracts).

${ }^{33}$ This estimate takes into account the direct costs incurred by firms, including third-party transaction costs. Also, while the estimate does not explicitly take into account additional litigation costs, more often than not this cost is implicitly added during severance negotiation. However, the estimate does not take into account the opportunity costs of firing - i.e., opportunities foregone because of resources used during the procedure, etc.
} 
The elasticity of job destruction (for CDD and CDI contracts) for low-wage employment is estimated at $1 \frac{1}{2}, 34$ and the elasticity of supply is taken to be 20 percent (Laroque and Salanié, 2000).

\section{B. Expected Impact in Job Creation}

We examine the impact of the CNE labor reform under two different scenarios. First, we assume that the reform has no influence on the size of the labor force. Next, we consider the more realistic situation in which the labor force is not constant, in order to better assess the underlying forces that affect unemployment and job creation.

\section{The Reform's effects on unemployment under a constant labor participation rate}

A large degree of uncertainty and imprecision exists as to which economic variables significantly influence the size of the labor force. This uncertainty justifies a first scenario in which we take the labor force to be unresponsive to any expected benefits or losses arising from the CNE's introduction into the labor market. Given this assumption, Figure 3 illustrates the impact of the CNE on employment in the non-agricultural for-profit sector. The left hand side of the figure shows the variation in the employment rate, which is equal to the ratio of the employed population to the working-age population. On the right, we have the number of jobs in the non-agricultural for-profit sector as a function of time after the introduction of the CNE (jobs start at the value of 16, and are expressed in millions). As we can see, employment increases abruptly during the first two years, stabilizes at its peak, and then slightly decreases. If we assume that the CNE contract is applied to the non-agricultural for-profit sector as a whole, then a long run projection predicts the creation of 100,000 jobs, which amounts to a 0.35 percent increase in employment. The CNE contract's strong initial impact reflects its capacity to create jobs in the short run. However, seeing as CNE contracts have a shorter life-span than CDI contracts, employers are compelled to actively substitute CDI contracts with CNEs, leading to an increase in job destruction (in the long run, CNE jobs represent18 percent of the labor pool, and slightly less than one out of two of these jobs endure the two-year trial period). job destruction is most apparent at the end of the first-two years, when employers must decide whether to terminate their CNE contracts (and hire new employees) or to convert these contracts into CDI.

A priori, our model only allows us to estimate the impact of the introduction of CNE-type contracts on the labor market as a whole. A more specific assessment of the contracts' impact on a particular segment of the labor market (such as that of small businesses, or of the youth) would require explicitly modeling both the segment of interest and the general model. That said, our model provides orders of magnitude for the labor reform's impact on employees working for small businesses of less than twenty employees. Given that these

\footnotetext{
${ }^{34}$ This means a 1 percent increase in the average salary would bring about a 1.5 percent increase in the job-destruction rate.
} 
Figure 3. Employment Rate and Number of Net Jobs Created After the Introduction of CNE-type Contracts in the For-Profit Sector With No Changes in the Participation Rate
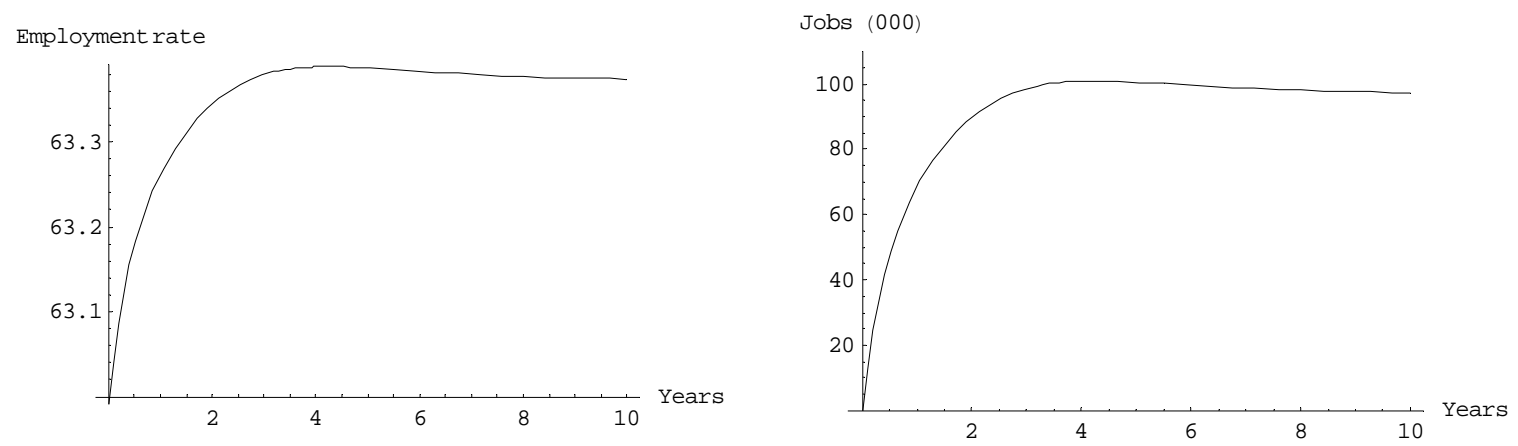

employees account for approximately one-third of all employees from the for-profit sector, a first estimate can be obtained by ignoring the potential specificity of small businesses. Namely, if we assume that one-third of the reform's global effect applies to small businesses, approximately 35,000 net jobs are expected to be created in the long run. Another approach would take into account the specificity of small businesses: the average length of employment is 83 months (as opposed to an average of 110 months, all firms considered), and $\mathrm{CDD}^{35}$ contracts represent 7 percent of all of their contracts (INSEE 2003 Enquête Emploi, a household survey on employment). With these specificities in mind, we estimate CNE contracts will have a more marked influence on small businesses; the reform could account for the creation of up to 70,000 net jobs (while small businesses only account for one-third of the total workforce). The CNE reform's more pronounced effect on job creation in the small-business sector can be explained by (1) the larger fluctuations in labor force participation and (2) the greater turnover rate found in this sector (which is approximately twice of that found in businesses of more than 20 employees). It follows that the introduction of flexible labor-contracts would benefit small businesses more than their larger counterparts.

\footnotetext{
${ }^{35} \mathrm{CDD}$ contracts with a duration of 30 days or more.
} 
Figure 4. Number of Net Jobs Created Following the Introduction of CNE-type Contracts for Firms of Less Than Twenty Employees in the For-Profit Sector

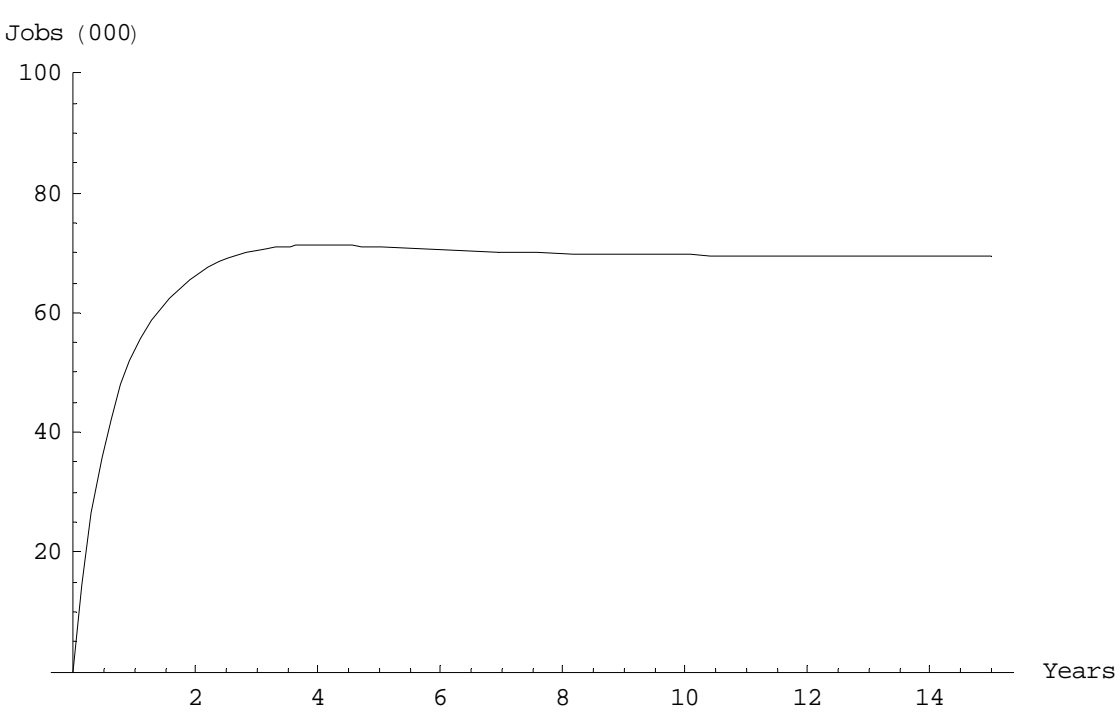

The Reform's effects on employment under a variable labor participation rate

We will now consider how the labor force participation rate might vary with the introduction of the CNE reform. In particular, we take the long-term elasticity of the labor participation rate (with respect to salary) to be equal to 20 percent. It is assumed that the participation rate gradually adjusts itself to the modifications introduced by the reform. In particular, we take the medium adjustment period as equal to six months. ${ }^{36}$

Figure 5 illustrates the consequences of introducing the CNE on the economy as a whole. Under this scenario, the reform's long-term effect is weaker since it reduces the labor participation rate. Namely, for reasons we will go into below, fewer people participate in the labor force after the reform, which reduces the overall level of employment. Still, under our current hypothesis of a variable participation rate, in the long run the for-profit sector could experience a net increase of 70,000 jobs. Overall, 10 years into the CNE labor reform, the employment rate is expected to have increased by 0.3 percentage points. These estimates vary according to certain hypotheses underpinning the model (see below).

\section{Expected Impact on Welfare and Labor Participation}

How the new labor contract will affect the living conditions of those participating in the labor market is a priori ambiguous. Two contending forces are at work: the CNE reform provides firms with more flexible contracts, which increase the quantity of jobs offered, in

\footnotetext{
${ }^{36}$ In other words, it takes six months for the labor participation rate to reach its midpoint (i.e., the average of its initial value and its steady-state value).
} 
Figure 5. Employment Rate and Number of Net Jobs Created After the Introduction of CNE-type Contracts in the For-Profit Sector With Changes in the Participation Rate
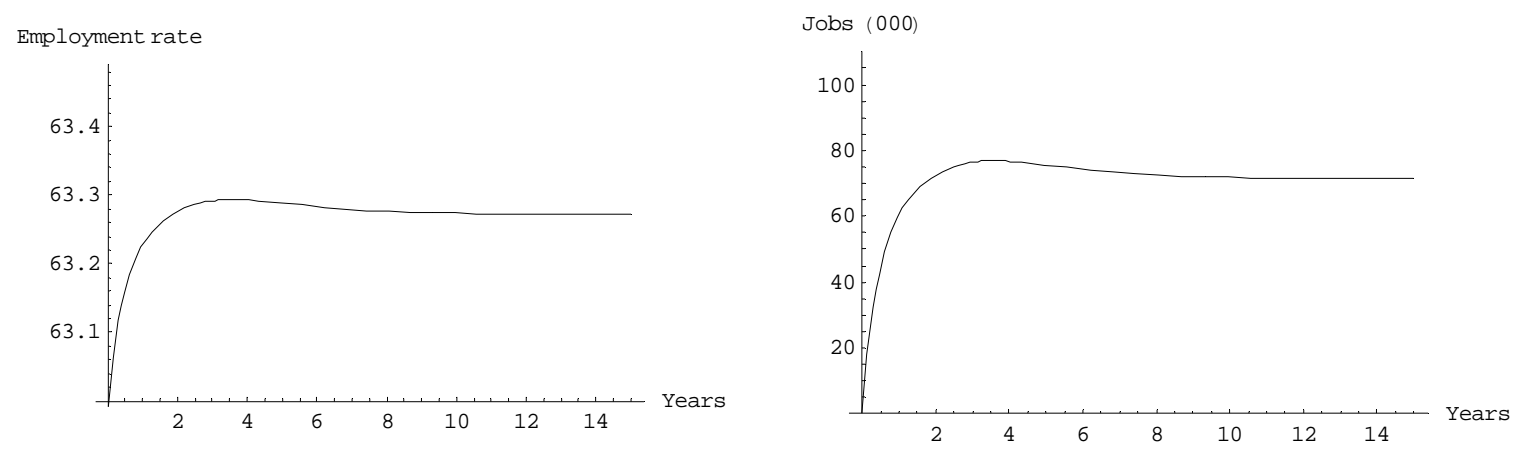

turn improving job prospects for job seekers. Still, the new employment offered is less stable, thus reducing labor force participants' living conditions.

Our model reveals that the latter, negative effect outweighs the former, resulting in a net decrease in living conditions for individuals in the workforce equivalent to 0.47 percent of their revenue. For some, this decrease in living conditions is incentive enough to leave the labor force, causing a slight decrease in the labor force participation rate. Figure 6 illustrates the evolution of the participation rate and the labor force after the CNE is introduced in the economy as a whole. The participation rate decreases slightly which translates to a reduction in the labor force of approximately 20,000 individuals. All things considered, introducing the CNE does not help firms hire employees more readily. On the contrary, by at once increasing firms' demand for work while decreasing the supply of labor, the CNE reform may be making it more difficult for businesses to hire.

\section{Expected Impact on Unemployment}

The labor reform's impact on the unemployment rate and the number of unemployed can be deduced from the evolution of employment and the participation rate after the CNE's

outset. Figure 7 illustrates this impact: the left hand side takes the labor participation rate as constant, while the right hand side allows this rate to vary.

When the participation rate is held constant, changes in unemployment can be directly drawn from variations in employment (as illustrated in Figure 3). An estimated improvement of 95,000 less unemployed individuals is expected in the long run if the reform is applied to the non-agricultural for-profit sector as a whole. Correspondingly, the unemployment rate decreases by approximately $1 / 2$ percentage points, bringing the long-term unemployment rate to $9 \frac{1}{2}$ percent.

Under the hypothesis of a variable participation rate, it turns out the number of unemployed individuals decreases by nearly the same amount as when the rate was held 
Figure 6. Participation Rate and Change in the Size of the Labor Force (in Thousands) Following the Introduction of CNE-type Contracts in the For-Profit Sector
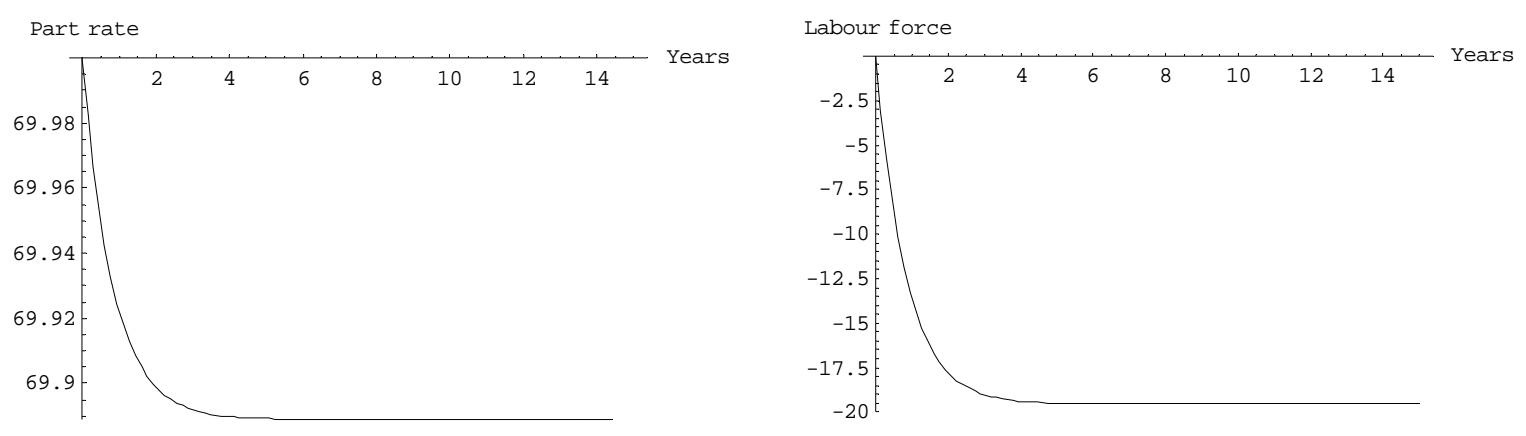

Figure 7. Unemployment Rate and Change in the Number of Unemployed Workers Following the Introduction of CNE-type Contracts in the For-Profit Sector With No Change in the Participation Rate
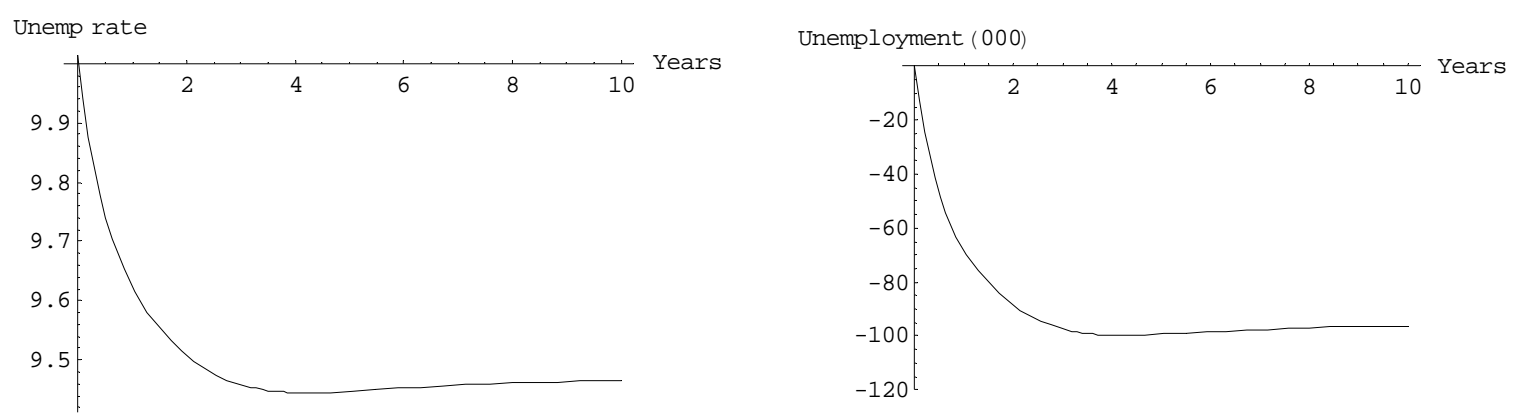
Figure 8. Unemployment Rate and Variation in the Number of Unemployed Workers After the Introduction of CNE-type Contracts in the For-Profit Sector With Changes in the Participation Rate.
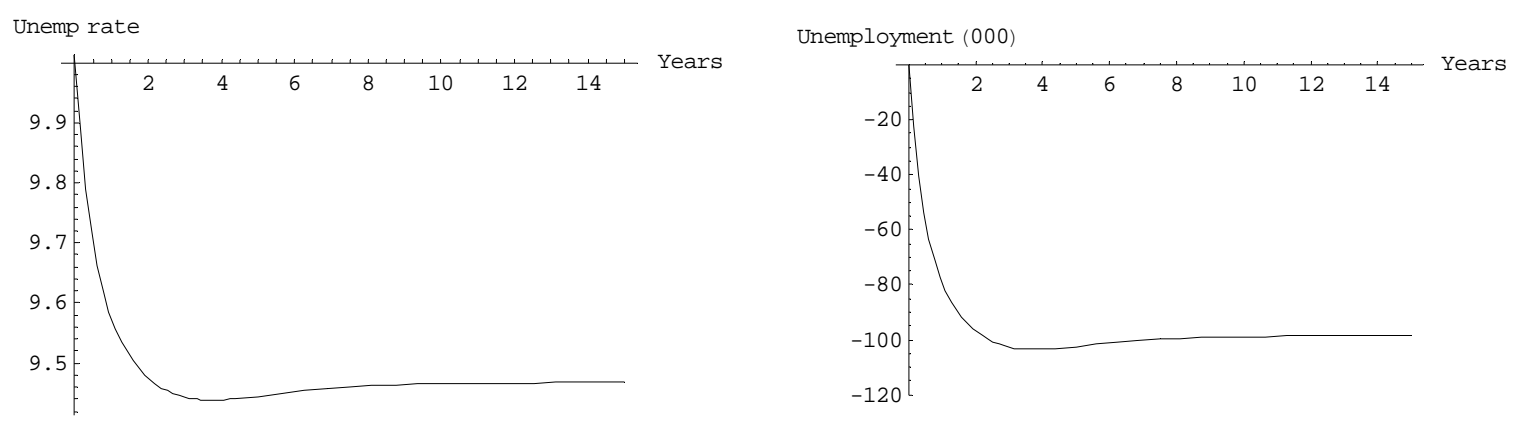

constant (Figure 8), even though the reform's impact on the level of overall employment is weaker due to the smaller labor force (Figure 5). In particular, the number of unemployed individuals decreases not only because of a greater rate of hire (which decreases with time), but also because a number of individuals leave the labor force. Thus, a drop in the number of unemployed individuals also depends on how the labor participation rate reacts to the labor reform. All in all, even under a variable participation rate, the model still estimates an overall improvement of 95,000 less unemployed individuals in the span of 15 years. Under the dual effect of temporarily renewed job creation and a reduction in the labor force, unemployment drops significantly during the first two years of the labor reform, but rises slightly afterwards.

The ratio of unemployed individuals to the labor force, that is the unemployment rate, also decreases. Soon after introducing the CNE, the unemployment rate drops appreciably under the combined effect of a temporary rise in the number of jobs and a reduction in the size of the labor force. But, as the end of the two year trial period draws near, the overall level of employment begins to decrease due to a drop in the participation rate, and the number of lay-offs increases, resulting in a rise in the unemployment rate. Ultimately, regardless of whether or not the participation rate is held constant, the unemployment rate stabilizes at a lower value than before the reform: the long-run equilibrium has been reached.

\section{E. Robustness of Results}

In order to evaluate the robustness of the results just presented, we must evaluate how these results react to minor changes in the calibrated values underpinning our model. Indeed, even if we sought to capture the chief characteristics of the French labor market as accurately as possible, the inherent degree of uncertainty that exists for each variable calls for the testing of alternate calibrations. 
Table 1 presents the CNE reform's long-term impact under calibrations that vary slightly from the original values adopted. As with the original calibration, each of the alternate calibrations are adjusted to capture the main characteristics of the French labor market before the introduction of the labor reform (employment and unemployment rates, duration of unemployment spells etc.). ${ }^{37}$ Table 1 indicates that doubling the labor-supply elasticity from 20 percent to 40 percent would lead to the creation of 45,000 new jobs in 10 years instead of the 70,000 jobs expected under the original calibration. Intuitively, if the supply of labor is more elastic to changes in the labor market, the anticipated decrease in welfare perceived by jobseekers after the CNE's introduction will lead to a greater number of people exiting the labor force. A decrease in the labor force is not conducive to increasing the overall level of employment.

The elasticity of job destruction with respect to salary is another variable whose true value is veiled in uncertainty. For the minimum wage sector of the labor market, we use Kramarz and Philippon's elasticity estimate of $1 \frac{1}{2}$. For wages higher than minimum wage, we can expect a lower elasticity, since firms benefit from the added possibility of lowering their employees' income instead of firing them altogether. For this sector of the labor market (above minimum-wage), the introduction of CNE-type contracts would have a more significant effect on employment than if the elasticity of job destruction were high, since lay-offs at the end of the trial period would be less frequent. To illustrate this point, we note that an elasticity of 1.3 leads to both a greater increase in employment $(+85,000)$ and a greater decrease in unemployment $(-115,000)$. Moreover, if we couple this lower elasticity with an expected 1 percent increase in salaries following the labor reform, the participation rate remains constant but fewer jobs are created $(+40,000)$. Table 1 reveals that under a higher elasticity of job destruction, the labor reform has a more modest effect on employment. For instance, if the elasticity is raised from 1.5 to 1.8 , the CNE's impact on employment is reduced from $+70,000$ to $+60,000$.

Our original hypothesis in which salaries do not change in response to the labor reform is undoubtedly an oversimplification. Seeing as the reform's affect on the unemployment rate is unambiguous (it decreases in all cases considered), we should expect a rise in salaries. In turn, this increase in salaries should curb the reform's impact on the unemployment rate. As evidence, we examine an exogenous 1 percent increase in salaries after the introduction of the CNE: only 30,000 jobs are created and the unemployment rate decreases by a meager 0.2 percent. An exogenous increase in salaries of 2 percent could even lead to an increase in unemployment.

\footnotetext{
${ }^{37}$ We adjust the values of $m_{0}, w, x_{\min }$ and $\lambda$ to reproduce the same labor characteristics as in the calibration of reference (see Appendix for definitions and values). The table is read as follows: in the first row the elasticity of job offers has a value of 0.2 under the base calibration, and the new value is 0.4 which accounts for an additional 45,000 jobs (versus $+70,000$ under the baseline calibration, as displayed in the last row).
} 
Table 1. The Robustness of the Model Under Different Parameter Values

\begin{tabular}{lccccccc}
\hline \hline Parameter & $\begin{array}{c}\text { Baseline } \\
\text { value }\end{array}$ & $\begin{array}{c}\text { New } \\
\text { value }\end{array}$ & $\begin{array}{c}\text { Emp } \\
(000)\end{array}$ & $\begin{array}{c}\text { Unemp } \\
(000)\end{array}$ & $\begin{array}{c}\text { Emp } \\
(\%)\end{array}$ & $\begin{array}{c}\text { Unemp } \\
(\%)\end{array}$ & $\begin{array}{c}\text { Labor force } \\
(\%)\end{array}$ \\
\hline Labor supply elasticity & 0.2 & 0.4 & +45 & -100 & 63.2 & 9.5 & 69.8 \\
Job destruction elasticity & 1.5 & 1.3 & +85 & -115 & 63.3 & 9.4 & 69.9 \\
Job destruction elasticity & 1.5 & 1.4 & +80 & -100 & 63.3 & 9.4 & 69.9 \\
Job destruction elasticity & 1.5 & 1.8 & +60 & -90 & 63.2 & 9.5 & 69.9 \\
Wage & $0 \%$ & $+1 \%$ & +30 & -30 & 63.1 & 9.8 & 70.0 \\
Wage & $0 \%$ & $+2 \%$ & +20 & +15 & 63.1 & 10.1 & 70.1 \\
Layoff costs CDI & $w$ & $w / 3$ & +20 & -25 & 63.1 & 9.8 & 70.0 \\
Layoff costs CDI & $w$ & $2 / 3 . w$ & +40 & -60 & 63.2 & 9.7 & 69.9 \\
CDD duration (month) & 8 & 10 & +75 & -100 & 63.3 & 9,5 & 69.9 \\
Arrival rate of shocks & 0.21 & 0.19 & +60 & -80 & 63.2 & 9.5 & 69.9 \\
Baseline calibration & & & +70 & -100 & 63.9 & 9.5 & 69.9 \\
\hline
\end{tabular}

In terms of severance costs, we have until now assumed that on average businesses pay the equivalent of one year's worth of salary to terminate a CDI contract. This hypothesis is drawn from the Kramarz and Michaud (2004) econometric study. In addition, we have assumed that $2 / 3$ of this severance cost goes to the employee as severance pay. If we were to assume that only half of the severance cost is allotted to the employee (i.e., six months worth of salary), we observe that the level of unemployment and the level of employment are nearly unchanged (the reform's effect on the employment rate is slightly weaker). Similarly, if we assume that the severance cost for businesses is less than a year's worth of salary, ${ }^{38}$ the results change only slightly. As illustrated in Table 1, when the severance cost is set at $2 / 3$ of annual salary, the reform would only create an estimated 40,000 net jobs; if the severance cost were to be reduced to $1 / 3$ of annual salary, the reform's impact on job creation is even more modest $(+20,000$ jobs). Thus, as was anticipated, the CNE reform is more effective the greater the CDI's severance costs.

In our original calibration, we took the average length of a CDD contract to be eight months (excluding CDDs of less than 30 days from our sample). However, this value varies depending on the source: in the INSEE 2003 Enquête Emploi the average length is reported as 10 months. Adopting this latter value, we find our results nearly unchanged (Table 1).

As was previously discussed when we considered small businesses, the effects of the CNE reform are more pronounced for businesses (and industries) with a high turnover rate - that is, businesses that have a greater need for flexible labor contracts. Moreover, industries in which businesses are rarely subject to productivity shocks or demand shocks will be less responsive to the CNE-type reforms (a net increase of 60,000 jobs instead of 70,000 if the arrival rate of shocks is 10 percent lower). ${ }^{39}$

\footnotetext{
${ }^{38}$ This assumption is justified in that firms of fifty or more employees are overrepresented in the data set used by Kramarz and Michaud (2004).

${ }^{39}$ Firms that have a smaller value of $\lambda$ (see Appendix).
} 


\section{Conclusion: The Advantages of a Single Labor Contract?}

Three main conclusions can be drawn from our analysis:

- First, the introduction of CNE reform in the French economy is expected to have a weak, positive effect on job creation a few years after its outset. Under the most realistic calibration of our model, the labor reform causes a slight increase in the overall level of employment, but reduces the size of the labor force in the long run.

- Next, the CNE reform makes most of its impact during the first two years of its existence. The significant, discontinuous jump in worker protection (e.g., severance costs for the firm) when moving from the extended trial period to a CDI contract stops the growth of employment two years after the reform was initiated and even induces a slight decrease from the third year onward. This threshold effect bears certain policy implications: when evaluating ex post the success of the CNE-labor reform, one should be careful and refrain from ascribing too much importance to results obtained just after a few months, seeing as the medium/long run effects of reform are likely to be more modest.

- Lastly, in making jobs less secure for employees, the labor reform is expected to have a negative impact on jobseekers' welfare. The increase in job insecurity is a direct result of the discontinuity in severance costs introduced by the reform - a discontinuity that incites firms to terminate contracts after the trial period.

Our conclusions are consistent with the extant literature on the consequences of extending the use of CDD contracts (Blanchard and Landier, 2002; Cahuc and Postel-Vinay, 2002). These studies suggest that policies which make the labor market more flexible at the margin are fairly ineffectual; such marginal reforms tend to artificially increase the turnover rate and have a very modest effect on job creation, while having potentially harmful effects on welfare. On the other hand, a more comprehensive labor reform may prove more fruitful. In particular, a reform that instituted a tax on layoffs as a substitute for (1) the internal reassignment of employees; and (2) substantial legal and administrative costs (the procedural costs), could reduce job instability and boost job creation (Blanchard and Tirole, 2003; Cahuc and Malherbet, 2004; Cahuc and Kramarz, 2005; Boeri and Garibaldi, 2006).

To further illustrate this type of results for France, we have simulated a more comprehensive reform that would have the ambition, in addition to the changes brought about by the CNE reform, of eliminating procedural severance costs in case of layoff for economic reasons (specifically, in the non-agricultural for-profit sector). As such, we assume employees would receive eight months of salary in case of severance, which 
corresponds to the current average payment. ${ }^{40}$ Besides, we assume firms would benefit from simplified procedures, ${ }^{41}$ which would reduce the cost of severing a CDI contract to eight months worth of salary in total (as opposed to 1 year worth of salary). As illustrated in Figure 9, such a reform is approximately four times more effective in creating jobs than the introduction of the CNE (+250,000 jobs). Moreover, individuals participating in the labor force would see their welfare unchanged, or even increase slightly by an amount equivalent to 0.11 percent of their income.

Figure 9. The Impact of the CNE Reform in the For-Profit Sector When Also Accompanied by (1) A Reduction of the Procedural Costs of Economically Motivated Dismissals and (2) Compensated by an Increase in the Legally Imposed Severance Pay
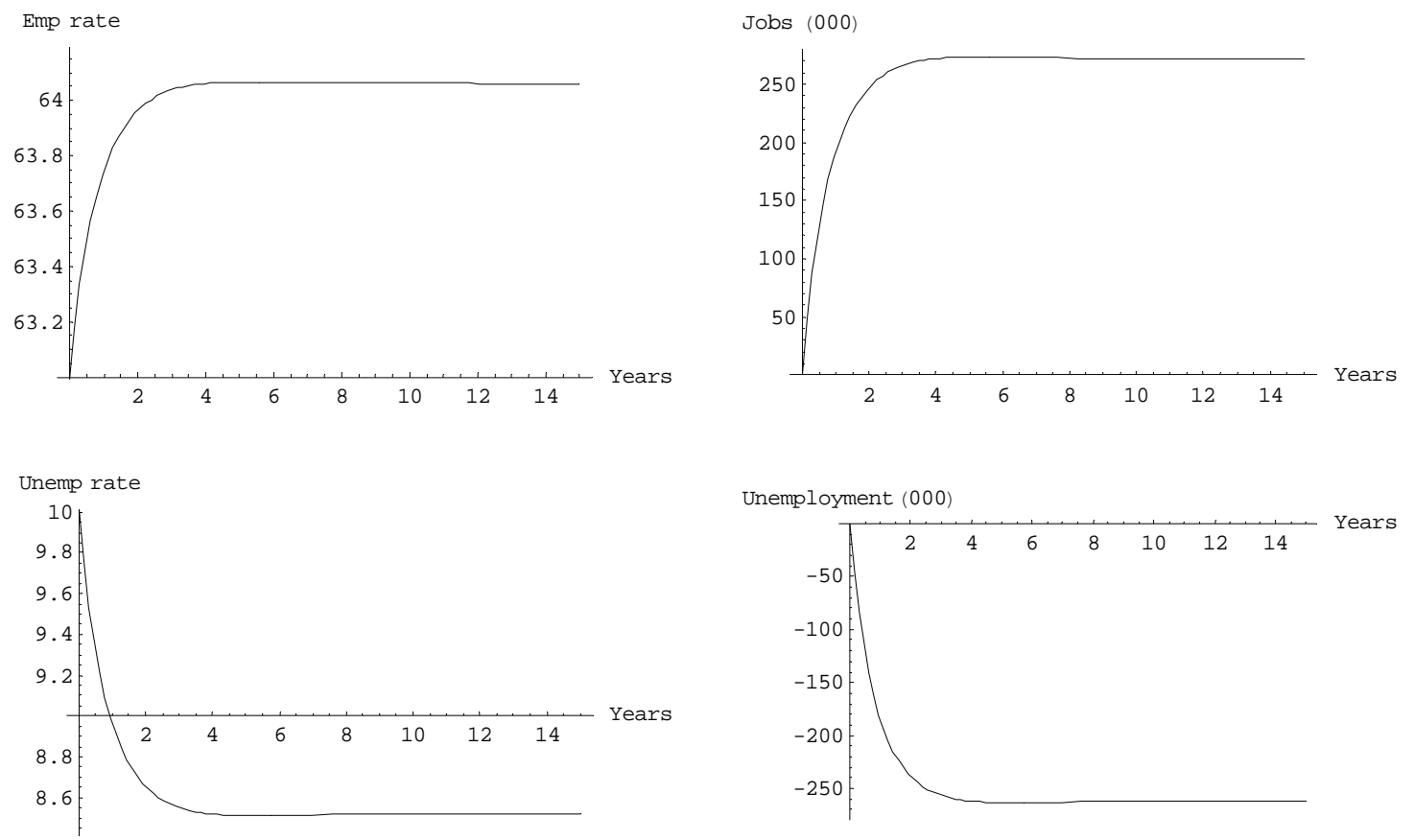

This latter scenario is an example of a single labor contract as put forth by Blanchard and Tirole (2003) and Cahuc and Kramarz (2004). These studies suggests that it is possible to implement a labor reform that significantly increases job creation and reduces the unemployment rate without decreasing jobseekers' welfare. Our projections indicate that under the current reform, CNE-type contracts fall short of this objective. However, another

\footnotetext{
${ }^{40}$ This figure is an average for the total CDI labor stock. Severance pay can increase with seniority. We also note that this figure is considerably higher than the explicit legal or conventional severance pay, as it also takes into account additional pay that generally arises from litigation and negotiation between the firm and the employee (see Kramarz and Michaud, 2004). In reality, only through an increase in the legally required amount of severance pay would we observe severance costs rise up to eight months worth of salary.

${ }^{41}$ See Cahuc and Kramarz (2005) on this point.
} 
reform complementing the introduction of the CNE may prove quite effective: striking a balance between substantially reducing the procedural costs of severing a contract and offering more generous severance pay seems to be the most promising way of ensuring both job creation and welfare improvement. 


\section{Appendix: The Model}

Drawing on Mortensen and Pissarides (1994), we adopt a matching function in continuous time with exogenous wages. There are two goods: labor and a numéraire good that is both produced and consumed. The size of the working-age population is labeled as $L$. Each agent is assumed to have an infinite life-span, and to discount time at a rate $r>0$. Job positions can be either filled or vacant. A vacant position costs the firm $h$ units of the numéraire good per unit of time. Vacant positions are assigned to unemployed individuals by the matching function, which determines the number of hires per unit of time based on the number of extant vacant positions and unemployed individuals. This function is continuously differentiable and increasing in both of its arguments, and exhibits constant returns to scale. Furthermore, we take labor market tightness, $\theta$, as equal to the ratio of vacant positions to unemployed individuals. Under these hypotheses, $\theta$ determines the rate at which an unemployed individual comes into contact with a vacant position. This rate is noted as $m(\theta)$, where $m$ is a continuous and decreasing function. The rate at which unemployed job seekers can meet jobs is thus $\theta m(\theta)$.

Each job produces $x$ units of the numeraire good per unit of time. The productivity of jobs changes at a rate $\lambda$. Given this rate of change, each new productivity $x$ is randomly drawn from a distribution with an interval noted $G: \mathbb{R}: \rightarrow[0,1]$.

We begin by representing the French labor market with CDD and CDI contracts. We then introduce CNE-type contracts into the labor market.

\section{A. The Labor Market With CDD and CDI Contracts}

We first define the value of employment in order to propose how the firm might evaluate the costs and benefits of creating or destroying jobs. In turn, this will enable us to determine the unemployment rate and the labor force participation rate.

\section{The value of employment}

We define the expected profit of a CDD contract $\Pi_{d}(x)$, via the Bellman equations. Wages and productivity are noted as $w_{d}$ and $x$ respectively. We have:

$$
r \Pi_{d}(x)=x-w_{d}+\lambda\left[\int_{-\infty}^{+\infty} \Pi_{d}(\epsilon) d G(\epsilon)-\Pi_{d}(x)\right]+\mu_{d}\left[\max \left[\Pi(x),-f_{d}+\Pi_{v}\right]-\Pi_{d}(x)\right]
$$

where $\mu_{d}$ is the rate of destruction of CDD, $\Pi(x)$ is the value of a CDI contract with productivity $x$, and $\Pi_{v}$ is the value of a vacant position. An individual whose CDD contract has been severed may either leave the firm or continue with the firm under a CDI; $f_{d}$ is the termination pay received by the employee at the end of the contract. The length of a CDD contract is then $1 / \mu_{d}$.

We assume that a CDI contract may be severed after a productivity shock, the firm incurring a total severance cost equal to $f$. This value is an average approximation, seeing 
as it does not take into account seniority (e.g., the legally imposed severance pay rises significantly after ten years of seniority). If $\Pi(x)$ is the value of a CDI contract with a productivity $x$, we have:

$$
r \Pi(x)=x-w+\lambda\left[\int_{-\infty}^{+\infty} \max \left[\Pi(\epsilon),-f+\Pi_{v}\right] d G(\epsilon)-\Pi(x)\right]
$$

where $w$ represents the wages received under the CDI. If we take $\Pi_{v}=0$, equation (2) can be expressed as follows:

$$
\Pi(x)=\frac{1}{r+\lambda}\left[x-w-\lambda f+\lambda \int_{R}^{+\infty} \frac{\epsilon-R}{r+\lambda} d G(\epsilon)\right]
$$

\section{Job destruction}

We establish a productivity threshold, $R$, where $\Pi(R)=-f$, and under which CDI contracts are destroyed:

$$
R=w-r f-\lambda \int_{R}^{+\infty} \frac{x-R}{r+\lambda} d G(x)
$$

Similarly, $R_{d}$ is the productivity threshold below which a CDD contract is not transformed into a CDI, which satisfies $\Pi\left(R_{d}\right)=-f_{d}$, or:

$$
R_{d}=R+(r+\lambda)\left(f-f_{d}\right)
$$

$\Pi_{d}(x)$ can be expressed in terms of the model's parameters (variables). We can distinguish between two cases.

Case 1. $\left.x \in]-\infty, R_{d}\right]$,

$$
r \Pi_{d}(x)=x-w_{d}+\lambda\left[\int_{-\infty}^{+\infty} \Pi_{d}(\epsilon) d G(\epsilon)-\Pi_{d}(x)\right]+\mu_{d}\left[-f_{d}-\Pi_{d}(x)\right]
$$

which implies

$$
\begin{aligned}
\int_{-\infty}^{R_{d}} \Pi_{d}(x) d G(x)= & \frac{1}{\mu_{d}+\lambda\left[1-G\left(R_{d}\right)\right]+r} . \\
& \left(\int_{-\infty}^{R_{d}}\left(x-w_{d}\right) d G(x)-\mu_{d} f_{d} G\left(R_{d}\right)+\lambda G\left(R_{d}\right) \int_{R_{d}}^{+\infty} \Pi_{d}(x) d G(x)\right)
\end{aligned}
$$

Case 2. $x \in\left[R_{d},+\infty[\right.$,

$$
r \Pi_{d}(x)=x-w_{d}+\lambda\left[\int_{-\infty}^{+\infty} \Pi_{d}(\epsilon) d G(\epsilon)-\Pi_{d}(x)\right]+\mu_{d}\left[\Pi(x)-\Pi_{d}(x)\right]
$$


which implies

$$
\begin{aligned}
\int_{R_{d}}^{+\infty} \Pi_{d}(x) d G(x)= & \frac{1}{\mu_{d}+\lambda G\left(R_{d}\right)+r} \cdot \\
& \left(\begin{array}{c}
\int_{R_{d}}^{+\infty}\left(x-w_{d}\right) d G(x)+\lambda\left[1-G\left(R_{d}\right)\right] \int_{-\infty}^{R_{d}} \Pi_{d}(x) d G(x) \\
\quad+\mu_{d} \int_{R_{d}}^{+\infty} \Pi(x) d G(x)
\end{array}\right)
\end{aligned}
$$

By eliminating the expression $\int_{-\infty}^{R_{d}} \Pi_{d}(x) d G(x)$ from equations (5a) and (6a) we obtain an explicit representation of $\int_{R_{d}}^{+\infty} \Pi_{d}(x) d G(x)$ :

$$
\begin{aligned}
\int_{R_{d}}^{+\infty} \Pi_{d}(x) d G(x)= & \frac{\mu_{d}+\lambda\left[1-G\left(R_{d}\right)\right]+r}{\left(\mu_{d}+\lambda+r\right)\left(r+\mu_{d}\right)} \\
& \left(\int_{R_{d}}^{+\infty}\left(x-w_{d}\right) d G(x)+\mu_{d} \int_{R_{d}}^{+\infty}\left(\frac{x-R}{r+\lambda}-f\right) d G(x)\right)+ \\
& \frac{\lambda\left[1-G\left(R_{d}\right)\right]}{\left(\mu_{d}+\lambda+r\right)\left(r+\mu_{d}\right)}\left(\int_{-\infty}^{R_{d}}\left(x-w_{d}\right) d G(x)-\mu_{d} f_{d} G\left(R_{d}\right)\right)
\end{aligned}
$$

this enables us to explicitly calculate $\Pi_{d}(x)$.

\section{Job creation}

We assume that firms can only hire employees under CDD contracts in a given proportion, $\alpha$. This proportion takes into account French regulation which legally limits a firm's recourse to CDD contracts (most legal provisions relate to the temporary nature of such contracts). New CDD contracts are drawn from the distribution $G$.

The value of a vacant position is expressed as follows:

$r \Pi_{v}=-h+m(\theta)\left[\alpha \int_{-\infty}^{+\infty} \max \left(\Pi_{d}(x), \Pi_{v}\right) d G(x)+(1-\alpha) \int_{-\infty}^{+\infty} \max \left(\Pi(x), \Pi_{v}\right) d G(x)-\Pi_{v}\right]$

Where $\theta$ is the tightness of the labor market, $m(\theta)$ is the probability of an unemployed individual discovering a vacant position, and $h$ is the recruitment cost.

We take $R^{c}$ as the threshold value of productivity, above which an individual is hired under a CDI contract. When $\Pi\left(R^{c}\right)=0$, we have

$$
R^{c}=R+(\lambda+r) f
$$

The threshold value of productivity above which workers are hired under a CDD, denoted by $R_{d}^{c}$, is such that $\Pi_{d}\left(R_{d}^{c}\right)=0$, which implies :

$$
R_{d}^{c}=w_{d}-\mu \max \left[\Pi\left(R_{d}^{c}\right),-f_{d}\right]-\lambda \int_{-\infty}^{+\infty} \Pi_{d}(x) d G(x)
$$


The value of a vacant position can thus be expressed as:

$$
r \Pi_{v}=-h+m(\theta)\left[\alpha \int_{R_{d}^{c}}^{+\infty} \Pi_{d}(x) d G(x)+(1-\alpha) \int_{R^{c}}^{+\infty} \Pi(x) d G(x)\right]
$$

The free-entry condition $\Pi_{v}=0$ can be written as:

$$
\frac{h}{m(\theta)}=\alpha \int_{R_{d}^{c}}^{+\infty} \Pi_{d}(x) d G(x)+(1-\alpha) \int_{R^{c}}^{+\infty} \Pi(x) d G(x)
$$

This last equation, given our representations for the value of jobs and the thresholds for their destruction, allows us to find the labor market's equilibrium tightness.

The equilibrium values for the variables $\theta, R_{d}, R, R_{d}^{c}, R^{c}$ are defined by a system of equations with (3), (4), (8), (9), (11).

\section{The workforce}

The labor force participation rate $\ell / L$ is obtained by analyzing the trade-off between entering and exiting the labor force. Individual preferences are represented by a utility function that is increasing and concave with respect to disposable income: $v(\cdot)+\chi \xi$ where $\xi \in \mathbb{R}$ is the value of leisure and $\chi$ is a dummy variable that takes on the value of zero if an individual partakes in the labor force, and the value of one otherwise. We assume that individuals not partaking in the labor force receive a constant flow of disposable income, $\chi$. There exist different values of $z$ and $\xi$. For each pair of values $z$ and $\xi$ is associated a value for inactivity, equal to the discounted value of utility when not active. The cumulative distribution function of the expected discounted utilities of inactive individuals is denoted by $F$. In this context, individuals decide to participate in the labor market if the expected discounted utility of jobseeking, noted $V_{u}$, is greater than their expected discounted utility when inactive. Therefore, the participation rate, $\ell / L$, is equal to $F\left(V_{u}\right)$.

We assume that the participation rate progressively takes on its long-term value, $F\left(V_{u}\right) .{ }^{42}$ This hypothesis is reasonable given imperfect information. Individuals outside of the labor force are not readily informed of labor market conditions; similarly, individuals within the labor force are not immediately aware of living conditions once they exit the labor market. In other words, the growth of the labor force can be expressed by the following differential equation:

$$
\dot{\ell}=\delta\left[L F\left(V_{u}\right)-\ell\right]
$$

Thus, we must define $V_{u}$ in order to establish the labor force participation rate. For theoretical purposes, we need to adopt a unique conception of severance pay, for firms

\footnotetext{
${ }^{42}$ Let us recall that $V_{u}$ is a forward looking variable which instantly jumps on its steady state value. Accordingly, in the absence of frictions, the labor force should instantly jump on its steady state value.
} 
disburse this pay to their employees for an infinitesimally brief amount of time. Namely, our simplifying assumption is that workers perceive severance pay as a constant flow of money equal to the discounted value of the severance pay they expect to receive throughout their career. This flow is noted as $\varphi$. Unemployed individuals receive an additional disposable income, $b$. Thus, the value function of unemployment, $V_{u}$ can be expressed as follows:

$$
r V_{u}=v(b+\varphi)+\theta m(\theta)\left[\alpha\left[1-G\left(R_{d}^{c}\right)\right]\left(V_{d}^{0}-V_{u}\right)+(1-\alpha)\left[1-G\left(R^{c}\right)\right]\left(V-V_{u}\right)\right]
$$

Where $V_{d}^{0}$ designates a CDD contract with a productivity level sufficiently high enough to ensure its change into a CDI once the trial period is over (because $R_{d}^{c}>R_{d}$ ). $V$ is the value of a CDI contract. $V_{d}^{0}$ satisfies

$$
r V_{d}^{0}=v\left(w_{d}+\varphi\right)+\lambda\left[\left[1-G\left(R_{d}\right)\right] V_{d}^{0}+G\left(R_{d}\right) V_{d}^{1}-V_{d}^{0}\right]+\mu_{d}\left(V-V_{d}^{0}\right)
$$

where $V_{d}^{1}$ stands of the value of a CDD contract with a productivity level too low to ensure its change into a CDI. The contract is severed at the end of the trial period:

$$
r V_{d}^{1}=v\left(w_{d}+\varphi\right)+\lambda\left[\left[1-G\left(R_{d}\right)\right] V_{d}^{0}+G\left(R_{d}\right) V_{d}^{1}-V_{d}^{1}\right]+\mu_{d}\left(V_{u}-V_{d}^{1}\right)
$$

and $V$ satisfies

$$
r V=v(w+\varphi)+\lambda G(R)\left(V_{u}-V\right)
$$

\section{Unemployment}

The unemployment rate is calculated from the equations tracing fluctuations in unemployment and the creation and destruction of each of the different contracts. We distinguish between the contracts as follows: $n_{d u}$ is the number of CDD contracts that were not subject to a productivity shock; $n_{d}$ is the number of CDD contracts that were subject to a productivity shock; $n$ represents the total number of CDI contracts; and $U$ is the sum of all unemployed individuals. We take the working-age population as constant, and equal to $L$; we note $\ell$ as the size of the labor force. If we assume that only unemployed individuals enter and exit the labor force, we have:

$$
\begin{gathered}
\dot{n}_{d u}=\alpha\left[1-G\left(R_{d}^{c}\right)\right] \theta m(\theta) U-\left(\lambda+\mu_{d}\right) n_{d u} \\
\dot{n}_{d}=\lambda n_{d u}-\mu_{d} n_{d} \\
\dot{n}=(1-\alpha)\left[1-G\left(R^{c}\right)\right] \theta m(\theta) U+\mu_{d} n_{d u}+\left[1-G\left(R_{d}\right)\right] \mu_{d} n_{d}-\lambda G(R) n \\
\dot{U}=\dot{\ell}+\mu_{d} G\left(R_{d}\right) n_{d}+\lambda G(R) n-\left(\alpha\left[1-G\left(R_{d}^{c}\right)\right]+(1-\alpha)\left[1-G\left(R^{c}\right)\right]\right) \theta m(\theta) U
\end{gathered}
$$

where

$$
U+n_{d u}+n_{d}+n=\ell
$$

and

$$
\dot{\ell}=\delta\left[L F\left(V_{u}\right)-\ell\right]
$$

The steady state unemployment rate, $u$, is equal to $U / \ell$, and is expressed as follows:

$$
u=\frac{1}{1+\theta m(\theta)\left(\frac{\alpha\left[1-G\left(R_{d}^{c}\right)\right]}{\lambda+\mu_{d}}+\frac{\lambda \alpha\left[1-G\left(R_{d}^{c}\right)\right]}{\mu_{d}\left(\lambda+\mu_{d}\right)}+\frac{(1-\alpha)\left[1-G\left(R^{c}\right)\right]}{\lambda G(R)}+\frac{\mu_{d} \alpha\left[1-G\left(R_{d}^{c}\right)\right]}{\lambda G(R)\left(\lambda+\mu_{d}\right)}+\frac{\alpha\left[1-G\left(R_{d}^{c}\right)\right]\left[1-G\left(R_{d}\right)\right]}{\left(\lambda+\mu_{d}\right) G(R)}\right)}
$$




\section{B. The Labor Market After the Introduction of the CNE}

The labor market equilibrium after the introduction of CNE-type contracts is determined using the same approach as above, where only CDD and CDI contracts were considered.

\section{The value of jobs}

Let $\Pi_{e}(x)$ be the value of a CNE position with productivity $x$. For the sake of clarity, we take $\Pi_{v}=0$ and consider Bellman's equation where

$r \Pi_{e}(x)=x-w_{e}+\lambda\left[\int_{-\infty}^{+\infty} \max \left[\Pi_{e}(\epsilon),-f_{e}\right] d G(\epsilon)-\Pi_{e}(x)\right]+\mu_{e}\left[\max \left[\Pi(x),-f_{e}\right]-\Pi_{e}(x)\right]$

where $w_{e}$ is the salary paid under a CNE contract, $f_{e}$ is the severance cost, and $\mu_{e}$ is the rate at which CNE contracts are transformed into CDI.

\section{Job destruction}

The productivity threshold, $R$, under which CDI contracts are destroyed, is still defined by equation (3). Moreover, we take $R_{t}$ as the productivity threshold under which $\mathrm{CNE}$ contracts are left to expire without being transformed into CDD. In particular, $\Pi\left(R_{t}\right)=-f_{e}$ which can be expressed as

$$
R_{t}=R+(r+\lambda)\left(f-f_{e}\right)
$$

Seeing as $\Pi_{e}(x)>\Pi(x)$, it follows that the "destruction threshold" for CNE contracts, $R_{e}$ such that $\Pi_{e}\left(R_{e}\right)=-f_{e}$, is less than $R_{t}$. In order to explicitly calculate the value of a CNE contract, we must thus distinguish between two cases:

Case 1: $x \in\left[R_{e}, R_{t}\right]$,

$$
r \Pi_{e}(x)=x-w_{e}+\lambda\left[\int_{-\infty}^{+\infty} \max \left[\Pi_{e}(\epsilon),-f_{e}\right] d G(\epsilon)-\Pi_{e}(x)\right]-\mu_{e}\left[f_{e}+\Pi_{e}(x)\right]
$$

By calculating the difference between $\Pi_{e}(x)$ and $\Pi_{e}\left(R_{e}\right)$, we can write:

Case 2: $x \in\left[R_{t},+\infty\right]$,

$$
r \Pi_{e}(x)=x-w_{e}+\lambda\left[\int_{-\infty}^{+\infty} \max \left[\Pi_{e}(\epsilon),-f_{e}\right] d G(\epsilon)-\Pi_{e}(x)\right]+\mu_{e}\left[\Pi(x)-\Pi_{e}(x)\right]
$$

we note that

$$
\Pi_{e}^{\prime}(x)=\frac{1+\mu_{e} \Pi^{\prime}(x)}{\mu_{e}+\lambda+r}=\frac{1}{\lambda+r}
$$

which implies

$$
\Pi_{e}(x)=\frac{x-R_{t}}{\lambda+r}+\Pi_{e}\left(R_{t}\right)=\frac{x-R_{t}}{\lambda+r}+\frac{R_{t}-R_{e}}{\mu_{e}+\lambda+r}-f_{e}
$$


therefore, the value of a CNE contract can be expressed as:

$$
\begin{aligned}
\Pi_{e}(x)= & \frac{1}{\mu_{e}+\lambda+r}\left\{x-w_{e}+\right. \\
& \lambda\left[\int_{R_{e}}^{R_{t}}\left(\frac{\varepsilon-R_{e}}{\mu_{e}+\lambda+r}-f_{e}\right) d G(\varepsilon)+\int_{R_{t}}^{+\infty}\left(\frac{\varepsilon-R_{t}}{\lambda+r}+\frac{R_{t}-R_{e}}{\mu_{e}+\lambda+r}-f_{e}\right) d G(\varepsilon)\right] \\
-G\left(R_{e}\right) f_{e} & \\
& \left.+\mu_{e}\left[\max \left[\frac{x-R}{r+\lambda}-f,-f_{e}\right]\right]\right\}
\end{aligned}
$$

and the destruction threshold for CNE-type contracts $R_{e}$, such that $\Pi_{e}\left(R_{e}\right)=-f_{e}$, is written as:

$$
R_{e}=w_{e}-r f_{e}-\lambda\left[\int_{R_{e}}^{R_{t}}\left(\frac{x-R_{e}}{\mu_{e}+\lambda+r}\right) d G(\epsilon)+\int_{R_{t}}^{+\infty}\left(\frac{x-R_{t}}{\lambda+r}+\frac{R_{t}-R_{e}}{\mu_{e}+\lambda+r}\right) d G(x)\right]
$$

\section{Job creation}

All new jobs are created using CNE contracts. The creation threshold for a CNE-contract respects $\Pi_{e}\left(R_{e}^{c}\right)=0$ and is expressed as:

$$
\begin{aligned}
R_{e}^{c}= & w_{e}+\lambda f_{e}-\lambda\left[\int_{R_{e}}^{R_{t}}\left(\frac{x-R_{e}}{\mu_{e}+\lambda+r}\right) d G(\epsilon)+\int_{R_{t}}^{+\infty}\left(\frac{x-R_{t}}{\lambda+r}+\frac{R_{t}-R_{e}}{\mu_{e}+\lambda+r}\right) d G(x)\right] \\
& -\mu_{e} \max \left[\Pi\left(R_{e}^{c}\right),-f_{e}\right]
\end{aligned}
$$

The value of a vacant position $\Pi_{v}$ corresponds to:

$$
r \Pi_{v}=-h+m(\theta)\left(\int_{R_{e}^{c}}^{+\infty} \Pi_{e}(x) d G(x)-\Pi_{v}\right)
$$

The free-entry condition, $\Pi_{v}=0$, is written as:

$$
\frac{h}{m(\theta)}=\int_{R_{e}^{c}}^{+\infty} \Pi_{e}(x) d G(x)
$$

Ultimately, the equilibrium values for the variables $\theta, R, R_{t}, R_{e}$ are defined by a system of four equations: (3), (12), (14), (16).

\section{The labor force}

The size of the labor force is calculated in the same manner as when the labor market consisted of only CDD and CDI contracts: the participation rate is equal to $F\left(V_{u}\right)$. We must thus calculate an unemployed individual's expected utility in the labor market with CNE contracts. The value of unemployment $V_{u}$ is expressed as:

$$
r V_{u}=v(b+\varphi)+\theta m(\theta)\left[1-G\left(R_{e}^{c}\right)\right]\left(V_{e}^{0}-V_{u}\right)
$$


Where $V_{e}^{0}$ equals the value of a CNE-job with a productivity level sufficiently high enough to ensure its survival into a CDI. We have:

$r V_{e}^{0}=v\left(w_{e}+\varphi\right)+\lambda\left[\left[1-G\left(R_{e}\right)\right] V_{e}^{0}+\left[G\left(R_{t}\right)-G\left(R_{e}\right)\right] V_{e}^{1}+G\left(R_{e}\right) V_{u}-V_{e}^{0}\right]+\mu_{e}\left(V-V_{e}^{0}\right)$

Where $V_{e}^{1}$ specifies the value of a CNE-job that will be severed after its trial period due to a low productivity level:

$r V_{e}^{1}=v\left(w_{e}+\varphi\right)+\lambda\left[\left[1-G\left(R_{e}\right)\right] V_{e}^{0}+\left[G\left(R_{t}\right)-G\left(R_{e}\right)\right] V_{e}^{1}+G\left(R_{e}\right) V_{u}-V_{e}^{1}\right]+\mu_{e}\left(V_{u}-V_{e}^{1}\right)$

The value of a CDI-contract is represented by:

$$
r V=v(w+\varphi)+\lambda G(R)\left(V_{u}-V\right)
$$

\section{Unemployment}

Unemployment is determined using the same approach as above (6.1.5) in which we considered the flow of job creation and destruction for each type of contract. Given that the destruction threshold and creation threshold for a CNE contract are different $\left(R_{e}\right.$ and $R_{e}^{c}$, respectively) - it is again helpful to distinguish between the contracts. We take $n_{e u}$ to be the number of CNE contracts which were no subject to productivity shocks; $n_{e}$ is the number of CNE contracts that underwent a productivity shock; $n_{e i}$ is the number of CDI contracts; $U$ captures the total number of unemployed individuals. As above, if we assume that only unemployed individuals enter and exit the labor force, we have:

$$
\begin{gathered}
\dot{n}_{e u}=\left[1-G\left(R_{e}^{c}\right)\right] \theta m(\theta) U-\left(\lambda+\mu_{e}\right) n_{e u} \\
\dot{n}_{e}=\lambda\left[1-G\left(R_{e}\right)\right] n_{e u}-\left[\lambda G\left(R_{e}\right)+\mu_{e}\right] n_{e} \\
\dot{n}_{e i}=\mu_{e}\left(n_{e u}+\frac{\left[1-G\left(R_{t}\right)\right]}{\left[1-G\left(R_{e}\right)\right]} n_{e}\right)-\lambda G(R) n_{e i} \\
\dot{U}=\dot{\ell}+\lambda G\left(R_{e}\right) n_{e u}+\left[\mu_{e} \frac{G\left(R_{t}\right)-G\left(R_{e}\right)}{\left[1-G\left(R_{e}\right)\right]}+\lambda G\left(R_{e}\right)\right] n_{e}-\left[1-G\left(R_{e}^{c}\right)\right] \theta m(\theta) U+\lambda G(R) n_{e i}
\end{gathered}
$$

where

$$
U+n_{e u}+n_{e}+n_{e i}=\ell
$$

Since the participation rate progressively reaches its long term value $F\left(V_{u}\right)$, the growth equation for the labor force is defined by the following differential equation:

$$
\dot{\ell}=\delta\left[L F\left(V_{u}\right)-\ell\right]
$$

The steady unemployment rate is expressed as:

$$
u=\frac{1}{1+\frac{\theta m(\theta)\left[1-G\left(R_{e}^{c}\right)\right]}{\lambda+\mu_{e}}\left[1+\frac{\lambda\left[1-G\left(R_{e}\right)\right]}{\lambda G\left(R_{e}\right)+\mu_{e}}+\frac{\mu_{e}}{\lambda G(R)}\left(1+\frac{\lambda\left[1-G\left(R_{t}\right)\right]}{\lambda G\left(R_{e}\right)+\mu_{e}}\right)\right]}
$$




\section{Transitory dynamics}

To calculate the transitory dynamics that occur between the two labor regimes (e.g., before and after the introduction of the CNE), we start by defining our initial conditions: the steady-state values predicted by our model for a labor market with exclusively CDD and CDI contracts. Next, we model a transition period during which it is no longer possible for the unemployed to be hired under a CDD or CDI contract.

In this context the system of equations that captures the dynamics of the stock of jobs under CDD contracts $\left(n_{d u}\right.$, and $\left.n_{d}\right)$, as well as of the stock of jobs under CDI contracts before the reform $(n)$, can be expressed as follows:

$$
\begin{gathered}
\dot{n}_{d u}=-\left(\lambda+\mu_{d}\right) n_{d u} \\
\dot{n}_{d}=\lambda n_{d u}-\mu_{d} n_{d} \\
\dot{n}=\mu_{d} n_{d u}+\left[1-G\left(R_{d}\right)\right] \mu_{d} n_{d}-\lambda G(R) n
\end{gathered}
$$

Similarly, the dynamics of the stock of jobs under CNE contracts $\left(n_{e u}\right.$ and $\left.n_{e}\right)$, as well as CDI contracts hired after the introduction of the labor reform $\left(n_{i}\right)$, is written as:

$$
\begin{gathered}
\dot{n}_{e u}=\left[1-G\left(R_{e}^{c}\right)\right] \theta m(\theta) U-\left(\lambda+\mu_{e}\right) n_{e u} \\
\dot{n}_{e}=\lambda\left[1-G\left(R_{e}\right)\right] n_{e u}-\left[\lambda G\left(R_{e}\right)+\mu_{e}\right] n_{e} \\
\dot{n}_{e i}=\mu_{e}\left(n_{e u}+\frac{\left[1-G\left(R_{t}\right)\right]}{\left[1-G\left(R_{e}\right)\right]} n_{e}\right)-\lambda G(R) n_{e i}
\end{gathered}
$$

At any given point in time, unemployment is defined by the identity:

$$
U=\ell-n-n_{d}-n_{d u}-n_{e}-n_{e u}-n_{e i}
$$

where $\ell$ is the number of individuals in the labor force, which is determined by a differential equation:

$$
\dot{\ell}=\delta\left[L F\left(V_{u}\right)-\ell\right]
$$

\section{Calibration}

The baseline parameter values are chosen to reflect the characteristics of the French labor market. The matching function is of the form $m(\theta)=m_{0} \theta^{-\eta}$ and the distribution of productivity shocks is taken uniform over $\left[x_{\mathrm{inf}}, 1\right] . F$ is a uniform function over the range $\left[V_{\text {inf }}, V_{\text {sup }}\right]$ The instantaneous utility function is expressed as $v(x)=x^{1-\sigma} /(1-\sigma)$, with $\sigma=2$.

We must choose the values of 15 parameters $r, f_{d}, f, \eta, z, \delta, \alpha, \mu_{d}, m_{0}, \lambda, h, x_{\text {inf }}, w, V_{\text {inf }}, V_{\text {sup }}$ (we assume $w_{e}=w_{d}=w$ ) 
The first six parameters are chosen as follows:

- the annual discount rate is $r=0.05$;

- the termination costs of a CDD contract $f_{d}$, equal to 10 percent of the total gross salary paid since the beginning of the contract, is expressed as $0.1 w / \mu_{d}$;

- the cost of severing a CDI contract, $f$, is equal to 100 percent of the annual salary: $2 / 3$ of this sum is paid to the dismissed worker, the remaining $1 / 3$ are procedural costs;

- the elasticity of the matching function is of the form $m(\theta)=m_{0} \theta^{-\eta}$, with $\eta=0.5$;

- the median adjustment time for the labor force $\Delta$ is taken to be six months, such that $\Delta=1 / 2$ which implies $\delta=2 / e^{\Delta}=1.2$;

- $b$ designates a jobseeker's immediate gain, which we take to be 70 percent of the salary $w$.

The remaining nine parameters are chosen to reflect:

- the proportion of jobs created under CDD contracts, $\alpha=0.7$;

- the duration of CDD contracts, $1 / \mu_{d}=1 / 1.5$ (i.e., 8 months);

- the unemployment rate $u=0.1$;

- the average duration of jobs, which is equal to 110 months. Since there is a transfer of $\mu_{d} G\left(R_{d}\right) n_{d}+\lambda G(R) n$ workers from employment into unemployment per unit of time, the average duration of employment (which is equal to the inverse of the average rate of job destruction) can be expressed as $\left(n_{d u}+n_{d}+n\right) /\left[\mu_{d} G\left(R_{d}\right) n_{d}+\lambda G(R) n\right]$;

- the proportion of CDD contracts in the total stock of jobs: $\left(n_{d u}+n_{d}\right) /\left(n_{d u}+n_{d}+n\right)$, equal to 5 percent;

- the duration of unemployment $1 / \theta m(\theta)\left[\alpha G\left(R_{d}^{c}\right)+(1-\alpha) G\left(R^{c}\right)\right]$, equal to 12 months;

- the elasticity of the rate of job destruction with respect to salary, i.e.,

$$
\frac{G^{\prime}(R)(\lambda+r) w}{G(R)[r+\lambda G(R)]} \frac{\mu_{d} G^{\prime}\left(R_{d}\right) n_{d}+\lambda G^{\prime}(R) n}{\mu_{d} G\left(R_{d}\right) n_{d}+\lambda G(R) n}
$$

which we assume to be equal to $1 \frac{1}{2}$ (see Kramarz and Philippon, 2003). We use short-run elasticity by (1) taking the appropriate stock of jobs; and (2) by taking into account only variations in productivity thresholds, which vary directly with changes in income;

- the participation rate $\left(V_{u}-V_{\mathrm{inf}}\right) /\left(V_{\mathrm{sup}}-V_{\mathrm{inf}}\right)$ is equal to 70 percent; 
- the elasticity of the participation rate with respect to salary is taken to be 0.2 .

Values for all fifteen parameters are presented in Table 2.

Table 2. Baseline Parameter Values for the Simulation of the Model

\begin{tabular}{lllllllllllllll}
\hline \hline$r$ & $f_{d}$ & $f$ & $\eta$ & $z$ & $\delta$ & $\alpha$ & $\mu_{d}$ & $m_{0}$ & $\lambda$ & $h$ & $x_{\text {inf }}$ & $w$ & $V_{\text {inf }}$ & $V_{\text {sup }}$ \\
0.05 & $\frac{0,1 w}{\mu_{d}}$ & $w$ & 0.5 & 0.7 & 1.2 & 0.7 & 1.5 & 0.772 & 0.211 & 0.1 & -0.395 & 0.48 & -165.1 & 11.42 \\
\hline
\end{tabular}

When the labor market includes CNE contracts, recall that these contracts must be transformed into CDI or terminated after an average of two years, such that $\mu_{e}=0.5$ The severance pay received by a worker is equal to 8 percent of his total gross salary, while the employers severance cost is 10 percent of the worker's total gross salary. These figures are calculated for the average duration of CNE contracts, estimated to be 1.62 years. 


\section{References}

Blanchard, Olivier, and Augustin Landier, 2002, "The perverse effects of partial labor market reform: Fixed duration contracts in France," Economic Journal, Vol. 112, pp. F214-44.

Blanchard, Olivier, and Jean Tirole, 2003, Protection de l'emploi et procédures de licenciements, rapport du Conseil d'Analyse Economique No44 (Paris: La documentation française).

Boeri, Tito, and Pietro Garibaldi, 2006, "Two Tier Reforms of Employment Protection Legislation. A Honeymoon Effects?" Mimeo, http://web.econ.unito.it/garibaldi/papers/honeymoon 30jan2006.pdf.

Cahuc, Pierre, and Francis Kramarz, 2005, De la précarité à la mobilité : vers une sécurité sociale professionnelle, Rapport au Ministre d'Etat, Ministre des Finances et de l'Industrie, et au Ministre de l'Emploi du Travail et de la Cohésion Sociale (Paris: La documentation française).

Cahuc, Pierre, and Franck Malherbet, 2004, "Unemployment Compensation Finance and Labor Market Rigidity," Journal of Public Economics, Vol. 88, pp. 481-501.

Cahuc, Pierre, and Fabien Postel-Vinay, 2002, "Temporary Jobs, Employment Protection and Labor Market Performance", with Fabien Postel-Vinay, Labour Economics, Vol. 9, pp. 63-91.

Goux, Dominique, Eirc Maurin, and Marianne Pauchet, 2001, "Fixed term Contracts and the dynamics of Labour Demand," European Economic Review, Vol. 45, pp. 533-52.

Kramarz, Francis, and Marie-Laure Michaud, 2004, "The Shape of Hiring and Separation Costs," CEPR Discussion Paper No. 3685 (London: Centre for Economic Policy Research).

Kramarz, Francis, and Thomas Philippon, 2001, "The Impact of Differential Payroll Tax Subsidies on Minimum Wage Employment," Journal of Public Economics, Vol. 82, pp.115-46.

Laroque, Guy, and Bernard Salanié, 2000, "Une décomposition du non-emploi en France", Economie et Statistique, Vol. 331, pp. 47-66. 
Mortensen, Dale, and Chritopher Pissarides, 1994, "Job Creation and Job

Destruction in the Theory of Unemployment," Review of Economic Studies, Vol. 61, pp. 397-415.

Pissarides, Christopher, 2000, Equilibrium Unemployment Theory (Cambridge, United States: MIT Press, 2nd ed.).

Zhou, Jian-Ping, 2006, "Reforming Employment Protection Legislation in France," IMF Working Paper No. 06/108 (Washington: International Monetary Fund). 